\title{
LOS ACUERDOS BILATERALES EN MATERIA DE ADOPCIÓN INTERNACIONAL FIRMADOS ENTRE ESPAÑA Y RUMANIA, PERÚ, COLOMBIA, ECUADOR, BOLIVIA Y FILIPINAS*
}

\author{
Nuria GONZÁLEZ MARTÍN**
}

\begin{abstract}
RESUMEN: Ante un nuevo derecho de familia internacionalizado, el artículo aborda un tema novedoso y poco estudiado por la doctrina como es la implementación de acuerdos bilaterales en concordancia con el artículo 39.2 del Convenio de La Haya de 29 de mayo de 1993, relativo a la protección de menores y la cooperación en materia de adopción internacional. En el artículo se analiza, de manera crítica, la labor de negociación bilateral en materia de adopción internacional realizada por España con diferentes países emisores de menores (Rumania, Perú, Colombia, Ecuador, Bolivia y Filipinas); acuerdos que, en principio, pretenden dar un mayor margen de seguridad, transparencia y cooperación en materia de adopción internacional.
\end{abstract}

ABSTRACT: In the face of a new internationalized family law, the article tackles a novel topic, insufficiently studied by the doctrine such as the implementation of bilateral agreements derived from article 39.2 of the Hague Convention of May 29, 1993, relative to the protection of children and intercountry adoption cooperation. In this article we analyze with a critical view, Spain's efforts in bilateral negotiations relative to intercountry adoption with a number of child emitting countries (Romania, Peru, Colombia, Ecuador, Bolivia, and Philippines); agreements that, in principle, are intended to provide greater margins of security, transparency and cooperation regarding intercountry adoption.

RÉSUMÉ: Devant le nouveau droit international de famille cet article nous montre une nouveaux sujet peu etudié par la doctrine comme est l'élaboration des accords bilatéraux dans l'esprit de l'article 39.2 de la Convention de La Haye du 29 mai 1993, relative à la protection des enfants en matière d'adoption internationalle. Dans l'article on analyse critiquement, les travaux de negociation bilattéral en matière d'adoption internationalle faite par l'Espagne avec différents pays qui émettre des enfants (Romanie, Pérou, Colombie, Éguateur, Bolivie et Philippines), accords qui, en principe, cherchent laisser de la marge pour la securité, la transparence, et la coopération en matière d'adoption internattionalle.

* El presente artículo forma parte de la investigación realizada durante la estancia sabática de la autora en España para la cual obtuvo el apoyo de la Dirección General de Asuntos del Personal Académico (DGAPA) de la UNAM, dentro del Programa de Apoyos para la Superación del Personal Académico (PASPA), con el proyecto titulado "Protocolo en materia de adopción internacional entre México y España". Un avance de este artículo lo podemos encontrar publicado con el mismo título en Calvo Caravaca, Alfonso-Luis y Castellanos Ruiz, Esperanza (dirs.), El derecho de familia ante el siglo XXI: Aspectos internacionales, Madrid, Colex, 2004, pp. 427-467.

** Investigadora del Instituto de Investigaciones Jurídicas de la UNAM.

Anuario Mexicano de Derecho Internacional, vol. V, 2005, pp. $221-278$ 
SUMARIO: I. Nota introductoria. II. Los acuerdos bilaterales en materia de adopción internacional firmados por España.

III. A modo de conclusión.

\section{NOTA INTRODUCTORIA}

El principio de protección del menor se ha convertido en referencia obligatoria, en cuanto al derecho internacional privado se refiere, al constatarse una serie de prácticas, ya generalizadas, en torno a la internacionalización de la condición del menor, ${ }^{1}$ al estar éste imbuido en prácticas habituales en donde se demandan, por ejemplo, derechos de custodia y visita, reclamaciones de alimentos, demandas por secuestro internacional de menores, tráfico de menores y adopción internacional, fundamentalmente.

La defensa del interés superior del niño a través del principio de protección del mismo es, y debe ser, la pieza clave en la promoción de los derechos de la niñez. Así se manifestó desde 1989 en la Convención de Naciones Unidas sobre los Derechos del Niño y así ha sido asumido por 192 Estados que ya son parte de la convención, alcanzando una ratificación cuasi universal. ${ }^{2}$

Cuando nos referimos a la adopción internacional que se da en la actualidad, siempre lo hacemos invocando el carácter de fenómeno social, ${ }^{3}$

1 Pérez Beviá, J. A. y García Cano, S., "Contribución de la Conferencia de la Haya a la globalización de los derechos del niño", en Calvo Caravaca, A. L. y Blanco-Morales Limones, P. (coords.), Globalización y derecho, Madrid, Colex, 2003, pp. 463 y 464.

2 Alegría Borrás, por su parte, expresa "lo limitado del Convenio de Naciones Unidas sobre los Derechos del Niño, dada la poca concreción de las obligaciones que impone y que constituye, sin duda, la razón de que haya tenido tantas ratificaciones en tan poco tiempo, ya que cuanto más concreto es un convenio y más estrictas las obligaciones que de él se derivan, mayores son las dificultades para su entrada en vigor y, en último término, para su eficacia", Borrás Rodríguez, A., "El 'interés del menor'como factor de progreso y unificación del derecho internacional privado", Revista Jurídica Catalana, 1994, p. 925. Sobre el Convenio de Naciones Unidas sobre el Derecho de los Niños de 1989, véase Díaz Barrado, "La convención sobre los derechos del niño", Estudios jurídicos en conmemoración del X Aniversario de la Facultad de Derecho, Córdoba, vol. I, 1991; Miralles Sangro, P. P., "La ratificación por España de la Convención de Naciones Unidas sobre los Derechos del Niño", Actualidad Civil, 1991, núm. 39; Bret, J. M., "La Convention des Nations Unies sur les droit de l'enfant: un texte aplicable et appliqué en France", Gaz du Pal, 1991; Rodríguez Benot, A., "La protección jurídica del menor en la Convención sobre los Derechos del Niño de 20 de noviembre de 1989", REDI, 1992, núm. 2.

3 Loon, J. H. A. van, "Rapport sur l'adoption d'enfants originaires de l'etranger. Document préliminaire 1 d'avril 1990", Actes et Document de la Dix-septième session, Conference de La Haya 
de situación atípica, quizás motivado por aquellos orígenes en los que la adopción no tenía razón de ser si no fuera por la necesidad de proseguir y perpetuar la estirpe familiar o por cuestiones sucesorias, entre otras. ${ }^{4}$ Nos encontramos ante una nueva situación que marca el paso de una "forma de perpetuación de la familia... a un sistema de protección". 5

A todo ello, a inicios del siglo XXI aunamos el concepto de globalización y/o integración al de la multiculturalidad y así aparece un nuevo concepto de familia y un nuevo derecho de familia internacionalizado.

Esto no quiere decir que con anterioridad no se concibiera un derecho de familia internacional sino que dado el trasiego transfronterizo actual, hay que redimensionar este fenómeno social, económico, jurídico y político.

De este contexto, como decimos, no se escapa la adopción, así la internacionalización de la misma se convierte en uno de los fenómenos que más acaparan la atención de los especialistas en la materia. Hablamos de un presupuesto importantísimo en derecho internacional privado de conexión entre una pluralidad de ordenamientos jurídicos; hablamos de una adopción transnacional y por ello intercultural e interracial.

Si el siglo XX se caracterizó por ser el siglo de la infancia, el siglo XXI debería poder caracterizarse, en un futuro próximo, como el siglo de la protección jurídica internacional de los menores.

La comunidad internacional a través de instrumentos como los convenios internacionales y los Estados a través de su legislación y práctica administrativa interna, deben centrarse, incondicionalmente, en la incorporación de todos aquellos elementos que garanticen una meta de máxima preferencia que es trabajar al unísono en interés de los menores.

Desde que España en 1995 firma y ratifica el Convenio de La Haya sobre la Protección de Menores y la Cooperación en Materia de Adopción Internacional, de 29 de mayo de 1993 (en adelante Convenio de La

de Droit International Privé, 1994, t. II, pp. 22-56; id., "International Co-operation and Protection of Children with Regard to Intercountry Adoption", RCADI, 1993, t. VII, pp. 214 y ss.

4 González Martín, N., “Adopción internacional”, Diccionario jurídico mexicano, México, UNAM, 2003 (en prensa).

5 Roca, E., Familia y cambio social, Madrid, Civitas, 1999, p. 255, citado por Guzmán Zapater, M., “Adopción internacional: ¿cuánto queda del derecho internacional privado clásico?”, en Calvo Caravaca A. L. e Iriarte Ángel, J. L. (eds.), Mundialización y familia, Madrid, Colex, 2001, p. 83. 
Haya de 1993), ${ }^{6}$ se han ido sucediendo una serie de hitos jurídicos que han sido determinantes a la hora de considerar la práctica de la adopción internacional. Nos referimos no sólo a la Ley 1/1996 de Protección Jurídica del Menor que modifica el artículo 9.5 del Código Civil, y a las leyes autonómicas que para tal efecto se reformaron, sino también a los diferentes protocolos o acuerdos bilaterales que España ha firmado en materia de adopción internacional, como un instrumento más de cooperación internacional, fundamento y objetivo del derecho internacional privado. $^{7}$

\section{LOS ACUERDOS BILATERALES EN MATERIA DE ADOPCIÓN INTERNACIONAL FIRMADOS POR ESPAÑA}

\section{Instrumentos de cooperación}

La práctica convencional bilateral española, en materia de tratados de cooperación procesal y sobre reconocimiento y ejecución de resoluciones extranjeras, ha sido muy abundante durante los últimos años.

6 En el presente artículo nos referimos sólo a España, ya que del título del mismo se deriva que el análisis, que en esta ocasión pretendemos realizar, versa sobre esta práctica bilateral española. Para una visión, a nivel general, sobre la perspectiva mexicana véase Péreznieto Castro, Leonel, "Algunos aspectos del derecho familiar en México y otro países de Latinoamérica", en Calvo Caravaca, Alfonso Luis y Castellanos Ruiz, Esperanza (dirs.), El derecho de familia ante el siglo XXI. Aspectos internacionales, Madrid, Colex, 2004, pp. 11-22, esp. 11-16; Silva, Jorge Alberto, "El impacto de los convenios internacionales sobre la legislación interna mexicana relativa a la adopción internacional de menores", Revista de Derecho Privado, México, nueva época, año II, núm. 4, enero-abril de 2003, pp. 151-195; Siqueiros Prieto, José Luis, "La Convención relativa a la Protección de Menores y a la Cooperación en Materia de Adopción Internacional", Jurídica. Anuario del Departamento de Derecho de la Universidad Iberoamericana, México, núm. 23, 1994; id., "La adopción internacional de menores", Revista de Investigaciones Jurídicas, México, año 17, núm. 17, 1993; id., "La cooperación judicial internacional. Expectativas para el siglo XXI", Revista Mexicana de Derecho Privado, México, número especial, 2000; González Martín, Nuria y Rodríguez Benot, Andrés (coords.), Estudios sobre adopción internacional, México, UNAM-Instituto Investigaciones Jurídicas, 2001.

7 Aguilar Benítez de Lugo, M., "La cooperación internacional como objetivo del derecho internacional privado", Cursos de Derecho Internacional de Vitoria-Gastéiz, 1991, pp. 171 y ss; id., "La cooperación internacional en derecho internacional privado", La cooperación internacional, XIV Jornadas de Profesores de Derecho internacional y Relaciones Internacionales (Vitoria, 26-28 de septiembre de 1991), Bilbao, Universidad del País Vasco, 1993, pp. 221 y ss., citado por Rodríguez Benot, A., "Tráfico externo, derecho de familia y multiculturalidad en el ordenamiento español", en varios autores, La multiculturalidad. Especial referencia al Islam, Escuela Judicial, Consejo General del Poder Judicial, 2002, Cuadernos de Derecho Judicial, vol. VIII, p. 53. 
Por lo anterior, España ha suscrito una diversidad de convenios bilaterales ${ }^{8}$ con: Alemania (14 de noviembre de 1983), ${ }^{9}$ Austria (19 de febrero de 1984), ${ }^{10}$ Brasil (14 de noviembre de 1989), ${ }^{11}$ Bulgaria (23 de mayo de 1993), ${ }^{12}$ Colombia (30 de mayo de 1908), ${ }^{13}$ Checoslovaquia (actualmente vigente con la República Checa y la República Eslovaca, de 4 de mayo de 1987) ${ }^{14}$ China (2 de mayo de 1992), ${ }^{15}$ Francia (28 de mayo de 1969), ${ }^{16}$ Israel (30 de mayo de 1989), ${ }^{17}$ Italia ( 22 de mayo de 1973), ${ }^{18}$ Marruecos (30 de mayo de 1997), ${ }^{19}$ México (17 de abril de 1989), ${ }^{20} \mathrm{Ru}-$ mania (17 de noviembre de 1997), ${ }^{21}$ Suiza (10 de noviembre de 1896), Uruguay (4 de noviembre de 1987) ${ }^{22}$ y la URSS (actualmente vigente únicamente para Rusia, de 26 de noviembre de 1990).

Nosotros, en esta ocasión, no nos vamos a referir a los convenios bilaterales mencionados sino a otro tipo de acuerdos que se gestan a tenor del artículo 39.2 del Convenio de La Haya de 1993, y que no han sido abordados extensamente por la doctrina más reconocida en la materia. Nos referimos a los denominados acuerdos o protocolos en materia de adopción internacional que surgen con un margen de reticencia o recelo por parte de los estudiosos en la materia y que nosotros pretendemos, con este trabajo, a salir a su rescate y destacar su valor y/o idoneidad.

8 "La política convencional bilateral referida surge con diferente vocación espacial, diferentes objetivos y ámbito de aplicación material, emplean diferentes técnicas y clases de normas en su redacción, y fundamentalmente, logran alcanzar distinta eficacia real". García Cano, Sandra, "Globalización, multiculturalismo y protección internacional del menor (evolución y futuro de los instrumentos jurídicos internacionales relativos a la protección del menor)", en Adam Muñoz, Ma. Dolores y García Cano, Sandra (dirs.), Sustracción internacional de menores y adopción internacional, Madrid, Colex, pp. 9-29

9 BOE, núm. 40, 16 de febrero de 1988. Corrección de errores $B O E$ de 24 de septiembre de 1992.

$10 B O E$, núm. 207, 29 de agosto de 1985.

$11 B O E, 10$ de julio de 1991. Corrección de errores $B O E$ de 13 de agosto de 1991.

$12 B O E$, núm. 155, 30 de junio de 1994.

13 Gaceta de Madrid de 18 de abril de 1909

14 BOE, núm. 290, 3 de diciembre de 1988.

15 BOE, núm. 26, 31 de enero de 1994.

16 BOE, núm. 63, 14 de marzo de 1970.

$17 B O E, 3$ de enero de 1991. Corrección de errores $B O E$ de 23 de enero de 1991.

18 BOE, núm. 273, 15 de noviembre de 1997.

19 BOE, núm. 150, 24 de junio de 1997.

20 BOE, 9 de mayo de 1989. Corrección de errores BOE 6 de mayo de 1991 y 20 de septiembre de 1991.

$21 B O E, 5$ de junio de 1997.

22 BOE, 30 de abril de 1998. 
España, en los últimos años ha iniciado una labor de negociación bilateral en materia de adopción internacional y ha concluido una serie de acuerdos orientados de manera específica a los problemas jurídicos inherentes a la misma. ${ }^{23}$ De hecho, el Convenio de La Haya de $1993^{24}$ señala las garantías que deben cumplirse y las vías de coordinación entre autoridades centrales en el que se incluye la suscripción de protocolos o acuerdos bilaterales en materia de adopción internacional.

Son acuerdos que nacen de la inquietud, de uno o de los dos Estados parte involucrados, en dar un margen más de seguridad, transparencia y cooperación en materia de adopción internacional. Estos acuerdos contribuyen, además, a una posible solución con respecto al tráfico de menores, siempre en clave de cooperación.

Por parte de España, la administración encargada fundamentalmente de dar curso a este tipo de iniciativa, ya sea vía diplomática, reuniones informales, etcétera, es el Ministerio de Trabajo y Asuntos Sociales

23 Cuartero Rubio, Ma. V., "Adopción internacional y tráfico de niños”, BIM, núm. 1840 (1o. de marzo de 1999), p. 408; Adroher Biosca, S., "Marco jurídico de la adopción internacional", en Gil-Robles Gil-Delgado, J. M. et al., Puntos capitales de derecho de familia en su dimensión internacional, Madrid, Dykinson, 1999, p. 107.

24 Además de los diferentes trabajos que se citan en el desarrollo de este artículo, recomendamos la lectura sobre el tema de Adroher Biosca, S., "La adopción internacional: una aproximación general", en Rodríguez Torrente, J. (ed.), El menor y la familia. Conflictos e implicaciones, Madrid, Universidad Pontificia de Comillas, 1998, pp. 209-304; Aguilar Benítez de Lugo, M. y Campuzano Díaz, B., "El certificado de idoneidad para las adopciones internacionales desde la perspectiva del derecho internacional privado", BIMJ, núm. 1888 (1o. de marzo de 2001), pp. 5-30; Álvarez González, S., Adopción internacional y sociedad multicultural, Madrid, Tecnos, 1999, 211 pp; Borrás Rodríguez, A., "El papel de la autoridad central: los Convenios de La Haya y España”, REDI, vol. XLV, 1993, pp. 63-79; Calvo Caravaca, A. L. e Iriarte Ángel, J. L. (eds.), Estatuto personal y multiculturalidad de la familia, Madrid, Colex, 2000; id., Mundialización..., cit., nota 5; Calvo Caravaca, A. L. y Blanco-Morales Limones, P. (coords.), Globalización..., cit., nota 1; González Beilfuss, C., "La aplicación en España del Convenio de La Haya de 29 de mayo de 1993 relativo a la protección del niño y a la cooperación en materia de adopción internacional", Revista Jurídica Catalana, núm. 2, 1996, pp. 9 y ss.; González Martín N. y Rodríguez Benot, A. (coords.), op. cit., nota 6; Loon, J. H. A. van, "Internacional Co-operation and Protection of Children vith Regard to Intercountry Adoptions", RCADI, 1993, t. VII, pp. 191-456; id., "Rapport sur 1'adoption d'enfants originaires de l'étranger", Actes et documents de la dic-septiéme session. 10 au 29 mai 1993, t. II: Adoption-cooperation, The Hague, Netherlands, Conference de La Haye de Droit Internacional Privé, Edit. Permanent Bureau of the Conference, 1994; Meyer Fabre, N., "La Convention de La Haye du 29 mai 1993 sur la protection des enfants et la coopération en matière d'adoption internationale", RCDIP, 1994, núm. 2, pp. 259-295; Rodríguez Benot, A., "Ley 18/1999, de 18 de mayo, de modificación del artículo 9, apartado 5o. del Código Civil en materia de adopción internacional", REDI, 1999, núm. 2, pp. 810-818; id., "La protección de los menores extranjeros en la comunidad autónoma de Andalucía”, en Rodríguez Benot, A. y Hornero Méndez, C. (eds.), La protección del menor en Andalucía. Tres estudios sobre la ley andaluza de los derechos y la atención al menor, Granada, Comares, 2000, entre otros. 
quien rubricará finalmente estos acuerdos o al menos los promoverá firmándolos otra dependencia ministerial, normalmente el Ministerio de Asuntos Exteriores.

El presupuesto del que se parte es el "giro copernicano" que ha sufrido en la actualidad la adopción internacional. Su evolución y proliferación ${ }^{25}$ ha provocado problemas de tal magnitud y variedad, de naturaleza tan distinta a las proyectadas décadas atrás, que no han podido ser resueltas por la normativa internacional anterior al Convenio de La Haya de 1993. ${ }^{26}$ El marco para el que fue diseñado el Convenio de La Haya de 15

25 Adroher Biosca, S., "Desafíos del derecho de familia en una sociedad intercultural", $F a$ milia e interculturalidad, Universidad Pontificia de Salamanca, 2003, col. Estudios familiares, núm. 13, pp. 315-363.

26 Desde principios del siglo XX, el siglo de la "infancia", son numerosos los instrumentos jurídicos internacionales concluidos en el marco de la protección del menor, tanto a nivel universal (Carta de los Derechos del Niño - 1924-, Declaración Universal de los Derechos del Niño —1959-, Convención de Naciones Unidas sobre los Derechos del Niño - 1989-, Protocolos Facultativos de la Convención sobre los Derechos del Niño - 2000_, y a través de la Conferencia de La Haya de Derecho Internacional Privado, los Convenios de La Haya de 12 de junio de 1902 sobre Tutela de Menores; de 5 de octubre de 1961, sobre Competencia de las Autoridades y la Ley aplicable en Materia de Protección de Menores; de 19 de octubre de 1996 relativo a la Competencia, la Ley aplicable, el Reconocimiento, la Ejecución y la Cooperación en Materia de Responsabilidad Parental y de Medidas de Protección de los Niños; de 25 de octubre de 1980, sobre los Aspectos Civiles de la Sustracción Internacional de Menores; de 15 de noviembre de 1965, relativo a la Competencia de Autoridades, Ley aplicable y Reconocimiento de Decisiones en Materia de Adopción; de 29 de mayo de 1993 relativo a la Protección del Niño y a la Cooperación en Materia de Adopción Internacional; de 24 de octubre de 1956 sobre la Ley aplicable a las Obligaciones Alimenticias respecto a Menores, y de 15 de abril de 1958, relativo al Reconocimiento y a la Ejecución de Decisiones en Materia de Obligaciones Alimenticias respecto a Menores) como a nivel regional (En América: Código de Bustamante hecho en La Habana el 20 de febrero de 1928, Tratado de Derecho Civil Internacional hecho en Montevideo en 1940, y las conferencias interamericanas: C. I. sobre Conflicto de Leyes en Materia de Adopción de Menores, hecha en la Paz el 24 de mayo de 1984 - CIDIP-III - ; C. I. sobre restitución de Menores, aprobada en Montevideo el 15 de junio de 1989 - CIDIP-IV - ; C. I. sobre Tráfico Internacional de Menores, aprobada en México el 18 de marzo de 1994 - CIDIP-V- En Europa: Consejo de Europa y su Convención Europea para la Salvaguarda de los Derechos Humanos y Libertades Fundamentales de 4 de noviembre de 1950; Convenio Europeo sobre Adopción de Menores de 24 de abril de 1967; Convenio Europeo sobre Repatriación de Menores de 28 de mayo de 1970; Convenio Europeo sobre el Estatuto Jurídico de los Niños nacidos fuera del Matrimonio de 15 de octubre de 1975, Convenio Europeo relativo al Reconocimiento y a la Ejecución de Resoluciones en Materia de Custodia, así como el restablecimiento de dicha custodia de 20 de mayo de 1980, Convenio Europeo sobre el Ejercicio de los Derechos del Niño de 25 de enero de 1996 y Convenio Europeo relativo a las Relaciones Personales del Menor de 14 de octubre de 2002. Unión Europea: Reglamento (CE) núm. 1347/2000 del Consejo, de 29 de mayo de 2000, relativo a la competencia, el reconocimiento y la ejecución de resoluciones judiciales en materia matrimonial y de responsabilidad parental sobre los hijos comunes). García Cano, S., "Globalización, multiculturalismo...", cit., nota 8. Véase, asimismo, Overbeck, A. E. von, "L'intérêt de l'enfant et l'êvolution du droit international privé de la filiation", 
de noviembre de 1965 sobre competencia de autoridades, ley aplicable y reconocimiento de decisiones en materia de adopción, cambió radicalmente. 27

Tenemos un Convenio de La Haya de 1993 que surge con un espíritu de "publificación" 28 reflejado, por ejemplo, en esa fase administrativa previa, y también nace, asimismo, con un espíritu de atracción de países de origen de los niños que no eran, incluso, Estados miembros de la Conferencia de La Haya en el momento de la firma del convenio. Se propició así la interactuación, casi por primera vez, entre Estados de recepción de los menores y Estados de origen de los mismos; la adopción internacional se constituye, a partir de ese momento, como un fenómeno mundial, social, caracterizado por "la migración de niños a través de grandes distancias geográficas y de una sociedad y cultura a un entorno social y cultural muy distinto"..$^{29}$

Definitivamente, la necesidad de cooperación entre los países de origen y de destino basado en relaciones de trabajo eficaces, en el respeto

Liber Amicorum Adolf F. Schnitzer, 1979, pp. 361-380; Moya Escudero, M., Aspectos internacionales del derecho de visita de los menores, Granada, Comares, 1998, pp. 6 y 7.

27 En cuanto a los defectos inevitables del convenio y a los problemas jurídicos que plantea, especialmente en los sectores del reconocimiento y la transformación de las adopciones, en comparación a la perfección técnica pero inútil del Convenio de 1965. M. Droz se expresaba de la siguiente manera: "La seule chose que je voudrias dire, est que vous avez parlé de la Convention de 1965 qui, effectivement, n'a pas très bien marché, elle n'est en vigueur que dans trois Etats, c'est à dire le Royaume-Uni, la Suisse et l'Autriche, les trois Etats où il n'y a pas d'enfant adoptable, ce qui fait que c'etait une belle Rolls Royce pour traverser le désert du Tiers Monde. Alors, nous avons préféré faire une quatre-quatre un peu de bric et de broc pour essayer de passer le désert" (ustedes han hablado del Convenio de 1965, que efectivamente no ha ido muy bien y que sólo ha entrado en vigor en tres Estados: Reino Unido, Suiza y Austria en los que no hay niños adoptables, ello suponía que se había fabricado un bonito Rolls Royce para atravesar el desierto del Tercer Mundo. Aquí hemos preferido fabricar un cuatro por cuatro un poco de aquí y de allá para tratar de atravesar el desierto) citado por Calvo Babío, Flora, Reconocimiento en España de las adopciones simples realizadas en el extranjero, Madrid, Dykinson, 2003, p. 76. Cfr. debate tras la comunicación de Muir Watt, H., "La Convention de la Haye du 29 mai 1993 sur la protection des enfants et la coopération en matière d'adoption internationale ", Travaux Com. fr. dr. Int. Pr., París, 1993-1995, p. 63.

28 Calvo Caravaca, A. L., "Globalización y adopción internacional", en Calvo Caravaca, A. L. y Blanco-Morales Limones, P. (coords.), Globalización..., cit., nota 1, pp. 25 y ss.; Carrillo Carrillo, B. L., Adopción internacional y el Convenio de La Haya de 29 de mayo de 1993, Granada, Comares, 2003, pp. 4 y ss.

29 Decimoséptima sesión — sesión plenaria-, Acta núm. 5 "Informe del secretario general sobre la cuestión de la adopción internacional de niños", pp. 271 y 272. Sugerimos la lectura de Trillat, B., "Una migration singuliére: l'adoption internationale", en Adoption des enfant etrangers, Seminaire Nathalie-Hasse 25-27 Mai 1992, París, Edit. Centre International de 1'Enfance, pp. $15-238$. 
mutuo y en la observancia de niveles profesionales y éticos elevados, ${ }^{30}$ marcaron el nacimiento de un convenio como el de 1993. ${ }^{31}$

México forma parte de ese listado de países considerados de origen, emisores de menores, y España engrosa el listado de aquellos países considerados receptores de menores a partir de la década de los noventa.

España se ha convertido en un país de una fuerte y creciente demanda de adopciones internacionales, cuestión que ha propiciado una regulación jurídica de esta figura cada vez más exhaustiva, vinculándose con los convenios internacionales más recientes en la materia.

Dado el interés que ambos países tienen en proteger a la infancia, este trabajo se completaría si se realizara, dado mi interés como investigadora en México, una propuesta o implementación de un protocolo adicional o acuerdo bilateral entre México y España, en materia de adopción internacional, de acuerdo al mencionado artículo 39.2 del Convenio de La Haya de 1993, que afine cuestiones puntuales de la práctica, no solventadas en los principios rectores del Convenio de La Haya de 1993; no obstante, por la extensión del artículo en sí no lo consideramos pertinente en esta ocasión, pero sí adelantamos que ya este estudio es objeto de una próxima publicación.

Una vez realizada esta puntualización, proseguimos con la idea de que no se puede, ni se debe obviar que en el tema de la adopción internacional hay una falta de información y por ello, una necesidad de incrementar la cooperación entre las administraciones públicas involucradas, con el fin de mejorar la información disponible sobre la infancia en general y la adopción en particular.

Poseer un sistema de comunicación posibilita compartir datos válidos y fiables, y permite, además, diseñar políticas de protección a la infancia sobre la base del conocimiento de las necesidades y problemas que definen una determinada situación, en este caso en relación a la adopción internacional, amén de abarcar otras cuestiones de relevancia tales como cumplir con los compromisos adquiridos con la ratificación de los convenios internacionales de protección al menor.

30 "Memoria sobre la preparación de un nuevo Convenio sobre la Cooperación Internacional y la Protección del Niño en Materia de Adopción Internacional, elaborado por la Oficina Permanente, noviembre de 1989, pp. 1 y 2.

31 Verwilghen, M., "La genèse d'une Convention sur l'adoption d'enfants originaires de l'étranger", RBDI, 1991, núm. 2, pp. 438-468. 
Como muestra de los acuerdos a los que se refiere el artículo 39.2 del Convenio de La Haya de 1993, tenemos que la administración española ha suscrito protocolos o acuerdos interestatales, bilaterales, en materia de adopción internacional con Rumania, Perú, Colombia, Ecuador, Bolivia y Filipinas ${ }^{32}$ que tienen, como una de sus finalidades, la instauración de un sistema de cooperación entre las partes que asegure en los procesos de adopción la total eliminación o al menos, la prevención de la sustracción, tráfico, trata y venta de menores de edad. Estos protocolos prevén, a su vez, en su articulado, un conjunto de comunicaciones entre las autoridades para una información precisa que no difiere, y que no debe diferir de la establecida en el Convenio de La Haya de 1993.

En sintonía con lo expuesto, y a modo de justificación para la continuación de este artículo, tal y como expresamos arriba, tenemos que México fue el primer país en firmar y ratificar el Convenio de La Haya, dado su interés como país emisor de menores, por consiguiente ¿por qué no implementamos medidas, en forma de protocolo adicional o acuerdos interestatales, bilaterales, para mitigar el problema efectivo que se da ante adopciones internacionales no demasiados claras, buscando siempre garantías encaminadas a desterrar el tráfico de menores?

Se trata de crear un clima de confianza mutua entre las autoridades involucradas, en este supuesto caso: México y España. Como comentamos, esto lo dejamos para una publicación que ya está próxima.

Con dicho Convenio de 1993, tenemos un tratado internacional cauteloso, respetuoso con el derecho interno de los países que forman parte de él, un convenio informador, transparente, de cooperación y de distribución de "responsabilidades", pero no queremos dejar de insistir y puntualizar que estos protocolos o acuerdos bilaterales son independientes de los cauces de protección establecidos en el Convenio de La Haya de 1993.

32 España ha firmado seis protocolos: con Rumania, de 2 de abril de 1993; con Perú, de 21 de noviembre de 1994; con Colombia, de 13 de noviembre de 1995; con Ecuador, de 18 de marzo de 1997; con Bolivia, el 29 de octubre de 2001 (este último sustituye a dos acuerdos anteriores de 5 de abril de 1995 y de 21 de mayo de 1997) Boletín Oficial del Estado, núm. 304, de 20 de diciembre 2001; y con Filipinas, de 12 de noviembre de 2002, Boletín Oficial del Estado, núm. 21, de 24 de enero de 2003 y entrada en vigor Boletín Oficial del Estado, núm. 265, de 5 de noviembre de 2003. 


\section{Contexto}

La adopción internacional en 2004 sigue siendo un fenómeno social, con un crecimiento realmente notorio en la sociedad española, de hecho las estadísticas indican que España es uno de los principales países receptores de menores a escala mundial, destinatario de un porcentaje que ronda el $17 \%$ de los niños adoptados en el mundo. ${ }^{33}$

Ante una realidad como la expuesta, se plantea la necesidad de abrir la posibilidad de adoptar en nuevos países ${ }^{34}$ o simplemente mejorar la calidad de las adopciones efectuadas con países que ya tienen una tradición en este aspecto con España, haciendo eficientes y ágiles sus actuaciones en materia de adopción internacional.

Por una parte, hablamos de calidad, en cuanto a constituir adopciones con todas las garantías y en interés superior del menor, en un tema tan delicado como son las adopciones internacionales, y así, de hecho, se tiene previsto, por ejemplo, en el mencionado artículo 39.2 del Convenio de La Haya de 1993, cuando expresa la posibilidad de que todo Estado contratante podrá concluir con uno o más Estados contratantes acuerdos para favorecer la aplicación del convenio en sus relaciones recíprocas y de esta manera siempre avanzar hacia una adopción internacional transparente, segura, ágil y eficiente.

Y también, por otra parte, hablamos de cantidad, y a tal tenor tenemos que los protocolos o acuerdos que analizaremos en las líneas siguientes tienen una gran importancia desde el momento que son países de origen de menores con una actividad de colocación realmente significativa.

La afirmación anterior se constata, con respecto a España, con las siguientes cifras: España, como Estado de recepción, tramitó en 2001 un total de 3,428 adopciones. Si agrupamos por continente el número de adopciones efectuadas durante 2001, tenemos que con América Latina se

33 Fuente: Ministerio de Trabajo y Asuntos Sociales. http://www.mtas.es

34 De hecho, las miras se tienen depositadas en países africanos como Namibia, Madagascar o Nepal, entre otros; y países asiáticos como Vietnam o Tailandia. También se nombran países de la Europa del Este como Moldavia o Kazahstan. González Beilfuss, C., "El protocolo de adopción internacional entre el Reino de España y la República de Filipinas", Revista Española de Derecho Internacional, España, 2003-1, vol. LV, pp. 585-589. 
constituyó un total de 721 adopciones; ${ }^{35}$ con Europa del Este, asimismo, un total de 1.569 adopciones $^{36}$ y con Asia un total de 1,107 adopciones. ${ }^{37}$

De todo ello, se deduce la necesidad de instaurar acuerdos como los firmados hasta la fecha por España con seis Estados de origen de los menores, en donde se valoren los términos cuantitativos y no se desprecie, por supuesto, el factor cualitativo. Si estos protocolos tienen naturalezas jurídicas diferentes unos de otros, ${ }^{38}$ quizás no resulte el dato de mayor relevancia en estos momentos, pero que cumplan un cometido de cooperación administrativa que facilite y agilice, como comentamos, la constitución de las adopciones internacionales sí debe de ser la pauta a seguir cuando de la protección de los menores hablamos.

\section{Apuntes sobre su naturaleza jurídica}

El precepto que regula la posibilidad de crear este tipo de acuerdos es el mencionado artículo 39, párrafo 2, del Convenio de La Haya de $1993,{ }^{39}$ a través del cual se introduce la posibilidad de concluir acuerdos

35 Con respecto a los países que forman parte de los protocolos en comento, tenemos en 2001: Bolivia, 18; Colombia, 319; Ecuador, 16; Perú, 71. La suma total de todos ellos, 424 adopciones, representa más del 50\% de las adopciones que se efectuaron en Latinoamérica. Fuente: Consulados españoles en el extranjero. Ministerio de Trabajo y Asuntos Sociales. http://www.mtas.es.

36 Con respecto a Rumania, país que forma parte de uno de los protocolos que comentamos, se realizaron un total de 373 adopciones.

37 En 2001, los datos que nos proporciona el Ministerio de Trabajo y Asuntos Sociales a través de su página $\mathrm{Web}$, anteriormente mencionada, refleja que con respecto a Filipinas — país encuadrado en el continente asiático y objeto, asimismo, de un protocolo firmado recientemente con España, que comentaremos en las páginas siguientes - no se efectuó ninguna adopción. Téngase en cuenta que este país contempla 400 colocaciones anuales. Véanse los datos estadísticos que proporciona su autoridad central, la Junta de Adopción Internacional (Inter-Country Adoption Board-ICAB) en su página Web, http://www.skyinet.net

38 Con respecto a la naturaleza jurídica, véase a Calvo Babío, F., "Naturaleza y alcance de los protocolos de adopción suscritos entre España y Colombia, Bolivia, Ecuador y Perú", Revista Española de Derecho Internacional, t. 0, 2000, pp. 455-464; id.,"Reconocimiento en España de las adopciones constituidas en Rumania: situaciones patológicas", La Ley, núm. 4628, 15 de septiembre de 1998, pp. 1-4; Esplugues Mota, C., "Conclusión por parte de España de cuatro protocolos sobre adopción internacional”, Revista Española de Derecho Internacional, 1996-2, pp. 336-340; Iriarte Ángel, J. L., "Adopción internacional”, en Calvo Caravaca, A. L. et al., Derecho internacional privado, 2a. ed., Granada, Comares, vol. II, pp. 146 y 147; González Beilfuss, C., "El protocolo de adopción internacional...", cit., nota 34 .

39 Artículo 39: "2. Todo Estado contratante podrá concluir con uno o más Estados contratantes acuerdos para favorecer la aplicación del convenio en sus relaciones recíprocas. Estos acuerdos sólo podrán derogar las disposiciones contenidas en los artículos 14 a 16 y 18 a 21. Los Estados que concluyan tales acuerdos transmitirán una copia de los mismos al depositario de la presente convención". 
futuros para favorecer la aplicación del Convenio de 1993, como un factor clave para garantizar la efectiva armonización normativa que subyace tras la elaboración de las normas convencionales. ${ }^{40}$

Con este artículo 39.2 se pretende respetar los vínculos tradicionales y los factores históricos, geográficos y de otro tipo que aproximan a determinados Estados contratantes. ${ }^{41}$

Los acuerdos permitidos por el párrafo 2, tan sólo pueden derogar las disposiciones contenidas en los artículos 14 a 16 y 18 a 21 (relativas a las condiciones del procedimiento) y esta interdicción se explica porque los futuros instrumentos internacionales no deben afectar a reglas fundamentales del convenio.

Por otra parte, pero siempre en cuanto a los acuerdos a los que se refiere el artículo 39.2, su entrada en vigor en uno de los Estados partes del Convenio de La Haya de 1993 no autoriza a los demás Estados contratantes a realizar la declaración prevista en el artículo 25 del mismo convenio de $1993 .{ }^{42}$

Tenemos entonces que esta última frase del párrafo 2, artículo 39, obliga a los Estados contratantes parte de dichos futuros acuerdos a transmitir una copia al depositario, para que éste pueda cumplir la tarea que le impone el apartado e) del artículo $48 .{ }^{43}$ Esto es de particular importancia puesto que permite a los Estados contratantes terceros realizar la declaración prevista en el artículo 25 , según la cual no estarán obliga-

40 Álvarez Rubio, J. J., "La interpretación y la traducción de las normas convencionales en el marco de la cooperación jurídica internacional", Anuario Español de Derecho Internacional Privado, t. 0, 2000, p. 222.

41 En la decimoséptima sesión, La Haya, 10-29 de mayo de 1993, se expresó que "debería de hablarse de antecedentes históricos, sin entrar en apreciaciones si son más o menos importantes dichos antecedentes. En la sesión, se mencionaba como más importantes los factores relacionados con los países nórdicos, Estados de la Unión Europea y los Estados surgidos de la antigua Unión de Repúblicas Socialistas Soviéticas, Checoslovaquia y Yugoslavia, y en menor medida se tomaron en cuenta por ejemplo aquellas relaciones entre Canadá y Estados Unidos de América o los Estados Unidos de América y México". Informe explicativo Parra-Aranguren, Convenio relativo a la Protección de Niños y a la Cooperación en Materia de Adopción Internacional de 29 de mayo de 1993, texto adoptado por la Decimoséptima Sesión, La Haya, Países Bajos, Oficina Permanente de la Conferencia, p. 132.

42 Artículo 25: "Todo Estado contratante puede declarar ante el depositario de la convención que no reconocerá en virtud de las disposiciones del mismo las adopciones hechas conforme a un acuerdo concluido en aplicación del artículo 39, párrafo segundo".

43 Artículo 48: "El depositario de la convención notificará a los Estados miembros de la Conferencia de La Haya de Derecho Internacional Privado así como a los demás Estados que se hayan adherido de conformidad con lo dispuesto en el artículo $44: .$. e) los acuerdos a que se refiere el artículo 39". 
dos por el convenio a reconocer las adopciones hechas conforme a tales futuros acuerdos.

El artículo 25 conecta con el artículo 39.2 y ambas disposiciones traducen, conjuntamente, el compromiso alcanzado entre los partidarios y adversarios de la posibilidad de acuerdos futuros entre Estados contratantes sobre materias reguladas por el convenio: 1) El artículo 39.2 autoriza estos acuerdos, dentro de ciertos límites, pero los demás Estados contratantes tienen derecho a declarar ante el depositario que no reconocerán en virtud del convenio las adopciones derivadas de tales acuerdos; 2) El artículo 25 exige una actuación positiva por parte del tercer Estado contratante, por tanto, en caso de que no se efectúe ninguna declaración, existirá una obligación convencional de reconocer las adopciones hechas conforme a los acuerdos autorizados por el párrafo 2 del artículo 39.44

El efecto de la declaración prevista en el artículo 25 consiste en que el tercer Estado contratante no estará obligado a reconocer las adopciones hechas conforme a los acuerdos concluidos en aplicación del artículo 39, párrafo 2. No obstante, no está prohibido reconocerlas de acuerdo con el derecho interno del Estado contratante que ha hecho la declaración. ${ }^{45}$

Por otro lado, aunque no se prevé de manera expresa, la declaración puede ser retirada en cualquier momento por el tercer Estado contratante que la efectuó, comunicándolo al depositario del convenio para que éste proceda a la notificación prevista en el apartado d) del artículo $48 .{ }^{46}$ Desde ese momento, el tercer Estado contratante estará obligado, en virtud

44 Informe explicativo Parra-Aranguren..., cit., nota 41, p. 100. La declaración ha de dirigirse al depositario del convenio, el Ministerio de Asuntos Exteriores del Reino de los Países Bajos, que informará a los Estados mencionados en el artículo 48. Por otra parte, el artículo 25 no especifica cuando ha de hacerse la declaración y por esto se pueden dar dos supuestos: 1. Cuando un Estado llega a ser parte del convenio y los demás Estados contratantes han concluido ya los acuerdos permitidos por el párrafo 2 del artículo 39; entonces, la declaración ha de hacerse en el momento de la ratificación, aceptación, aprobación o adhesión al convenio. Es posible también hacerlo después, pero entonces la declaración tan sólo tendrá efectos para el futuro, y el tercer Estado contratante estará obligado a reconocer, en virtud del convenio, las adopciones hechas, conforme a estos acuerdos, posteriores al momento en el que el nuevo Estado contratante ha llegado a ser parte del convenio y anteriores a la realización de la declaración. 2. Cuando un Estado ya es parte del convenio porque concluyen entre un Estado contratante y uno o más Estados contratantes los acuerdos autorizados por el párrafo 2 del artículo 39; en este supuesto ha de hacerse la declaración tan pronto como sea posible, a partir del momento en que el Estado contratante tercero recibe del depositario la notificación prescrita por el artículo $48 \mathrm{~d}$ ).

45 Ibidem, p. 101.

46 Idem. 
del convenio, a reconocer las futuras adopciones hechas conforme a estos acuerdos, pero el convenio no dice nada respecto a las adopciones posteriores.

En el artículo 39.2 in fine, no se establece un plazo para la transmisión de la copia ni tampoco se prevé ninguna sanción para el supuesto de violación de la obligación impuesta a los Estados contratantes que concluyan dichos acuerdos futuros.

Desde ya vemos que calificar y analizar la naturaleza jurídica de aquellos acuerdos que nacen con esta clara vocación de nivelar los desequilibrios demográficos y socioeconómicos del mundo actual no es tarea fácil.

La doctrina española no ha sido prolífica a la hora de analizar los diferentes protocolos o acuerdos firmados con los seis países mencionados anteriormente, de hecho vemos que aún no está superada la polémica en torno, precisamente, a la calificación de dichos acuerdos. Entre las diferentes posturas expresadas por la doctrina, tenemos quien ubica a algunos de ellos como un verdadero tratado internacional, acuerdo administrativo o de ejecución y/o acuerdo no-normativo.

Del análisis de cada uno de estos acuerdos podremos, quizás, llegar a conclusiones divergentes. Cada uno de estos protocolos, acuerdos, pactos, etcétera, podrán poseer una naturaleza jurídica diferente, con un alcance, obviamente, diferente.

Lo cierto es que el artículo 39.2 del Convenio de La Haya de 1993 no especifica la naturaleza jurídica que debe revestir este tipo de acuerdo, si deben ser tratados internacionales, per se, si acuerdos administrativos, acuerdos no-normativos o cualquier otro. Se menciona la necesidad de respetar los vínculos tradicionales, históricos, geográficos, etcétera que pueden aproximar a determinados Estados contratantes y de ahí la idoneidad de concluir, por ejemplo, acuerdos que contribuyan a la protección de sus menores. ${ }^{47}$

En cambio, los trabajos preparatorios sí se detienen, expresamente, en las condiciones que deben cumplir, dichos acuerdos, para que se consideren elaborados de conformidad al artículo 39.2, y estas condiciones son:

1. Han de ser posteriores a la entrada en vigor del Convenio de La Haya de 1993 en los Estados participantes; 
2. Deben tener como objetivo favorecer la aplicación del mismo en las relaciones recíprocas; y

3. Se establece de forma imperativa (no se precisa si para que tenga validez, o a efectos meramente informativos) el deber de transmisión de estos acuerdos al depositario del convenio para que éste pueda darles publicidad según el artículo 48 e) del mismo cuerpo legal. ${ }^{48}$

Vayamos por partes y veamos cuál puede ser, desde nuestra perspectiva, el alcance y naturaleza jurídica de estos protocolos o acuerdos.

En primer lugar, vamos a recopilar los datos más significativos manifestados por la doctrina que se abocó al análisis de los acuerdos que comentamos.

Comenzamos analizando las manifestaciones vertidas en los informes explicativos del Convenio de La Haya de 1993 y en los diferentes documentos de trabajo, y de ahí destacamos un dato significativo cuando se dice que los acuerdos, a los que se refiere el artículo 39.2 del Convenio de La Haya de 1993, tan sólo pueden derogar las disposiciones contenidas en los artículos 14-16, 18-21 (relativas al procedimiento) del Convenio de La Haya de 1993, porque los futuros instrumentos internacionales no deben afectar reglas fundamentales del propio Convenio de 1993.49

De esta afirmación textual, no del convenio sino de los informes explicativos, podemos extraer un argumento convincente en el sentido que los expertos que presenciaron y trabajaron en las diferentes comisiones preparatorias del Convenio de La Haya de 1993 tenían en mente instrumentos internacionales, acuerdos internacionales, tratados sujetos de derecho internacional; del "espíritu" del legislador al redactar el artículo 39.2 se podría inferir cuál fue la voluntad en la calificación de estos acuerdos.

Pero aquí no se trata de inferir o vaticinar aquello que no expresa la ley, como tal, textualmente. La práctica llevada a cabo en este sentido desde 1993 nos podrá ayudar a clarificar la voluntad de ubicar a los mis-

48 "Rapport Parra-Aranguren", Actes et Documents de la Dix-septième Session de la Conference de la Haye de Droit International Privé, t. II, pp. 641 y 642.

49 Idem; Informe explicativo Parra-Aranguren..., cit., nota 41, p. 133; Bureau Permanent, "Conclusions de la Commission spéciale de juin 1990 sur l'adoption d'enfants originaires de l'etranger, Document preliminarie núm. 3 d'aout 1990", Actes et Documents de la Dix-septiénme Session, t. II, Conférence de La Haye de Droit International Privé, 1994, pp. 128-135. 
mos y así poder darle la dimensión que precisan, en cuanto a los derechos y obligaciones que llevan implícitos.

Siguiendo con los comentarios extraídos de los informes explicativos, resaltar, por otra parte, la opinión vertida en el sentido de que "el segundo párrafo del artículo 39 implica una restricción importante de la regla del artículo 41, primer párrafo, primera frase, del Convenio de Viena sobre el Derecho de los Tratados de Naciones Unidas, que reconoce, en principio, la libertad de los Estados para concluir tratados multilaterales o bilaterales derogando un convenio multilateral existente". ${ }^{50}$

En realidad, el Convenio de La Haya de 1993 no contiene disposición alguna respecto a la relación con tratados futuros sobre materias regidas por él, por ejemplo respecto a un nuevo Convenio General de Protección de Menores, que en tal caso se aplicarán las reglas generales del derecho de los tratados a tenor del artículo 30 del Convenio de Viena sobre el Derecho de los Tratados. ${ }^{51}$

Si interpretamos ambas "restricciones" (artículo 41.1 y artículo 30 del Convenio de Viena) en sentido negativo y así descartamos la idoneidad de calificar a dichos acuerdos como tratados sujetos de derecho internacional, tratados internacionales, la siguiente reflexión vendría dada en el sentido que debe ser la voluntad de las partes la que determine su alcance.

Marina Hernando al hablarnos sobre los protocolos o acuerdos suscritos con España en materia de adopción internacional menciona que si bien dichos protocolos ${ }^{52}$ no tienen:

Consecuencias jurídicas entre los Estados, en caso de incumplimiento, al no tratarse de convenios o tratados sino sólo de protocolos o cartas de intenciones, es claro que las instituciones extranjeras que lo firman tienen la absoluta voluntad de exigir la intervención de la administración española en todos los expedientes de adopción, con lo que se consigue el mismo objetivo que si fueran convenios. ${ }^{53}$

50 Informe explicativo Parra-Aranguren..., cit., nota 41, p. 134.

51 Idem.

52 No se refiere, por la fecha de su artículo, a los más recientes firmados con Bolivia y Filipinas. Sobre el derecho de los tratados recomendamos la lectura de los numerosos artículos publicados por Sáez de Santamaría; en especial, Sáez de Santamaría, P. Andrés, "Jurisprudencia española de derecho internacional público", REDI, vol. XLIV, 1992, núm. 1, pp. 131-135.

53 Marina Hernando, A., "La adopción internacional. El trafico internacional de menores. Mecanismos de protección y control”, Infancia y Sociedad. Revista de Estudios, núm. 33, 1995. 
Es decir, depende, en cada caso, de la voluntad de las partes con respecto a la vinculación y obligatoriedad al mismo, su consideración como un verdadero convenio, como un verdadero tratado internacional. Estamos hablando ya de un acuerdo administrativo en el que la voluntad de las partes realmente va a determinar si se concibe como un auténtico tratado internacional. ${ }^{54}$ Una observación pertinente, sin ánimo de robarle credibilidad al acuerdo administrativo, es precisamente que no tienen todos contenidos de idéntica naturaleza, de ahí que la voluntad sea determinante para ubicarlos como tratados sujetos de derecho internacional.

Estos acuerdos administrativos serían tratados internacionales siempre y cuando el acuerdo derivara de un previo tratado concluido de acuerdo a las prescripciones constitucionales, v. g. Convenio de La Haya de 1993. Verdaderos tratados en los que se simplifica el proceso de celebración, sustituyéndose la plenipotencia del ministro de Asuntos Exteriores por una simple credencial del titular del departamento interesado, entendiéndose que la autorización para negociar un tratado-marco, concedida por el Consejo de Ministros, se extiende implícitamente a sus acuerdos de desarrollo y ejecución que, una vez concluidos, deben ser comunicados inmediatamente a las cámaras. ${ }^{55}$

Si el acuerdo administrativo se concibe (voluntad para concebirlo) como un auténtico tratado internacional, se podrían dar dos ventajas de relevancia a nivel practico: en la fase de negociación del acuerdo, la autorización para negociar podría simplificarse tal y como acabamos de

54 Remiro Brótons, A., "De los tratados a los acuerdos no normativos", en varios autores, $L a$ celebración de tratados internacionales por España: problemas actuales. Actas del Seminario organizado por el Ministerio de Asuntos Exteriores, el Ministerio de Relaciones con las Cortes y de la Secretaría de Gobierno y el Instituto Nacional de Administración Pública, Madrid, 1990, p. 38. Recordemos, por otra parte, el dictamen del Consejo de Estado núm. 55.253 de noviembre de 1990 en el que se expresaba: "No todo acto de ejecución de un tratado realizado de común acuerdo por órganos de las administraciones públicas de las partes contratantes constituye un convenio internacional..., pues existen numerosos tratados cuya ejecución no se realiza unilateralmente por cada uno de los Estados contratantes, sino que se confía a la constante colaboración de los órganos de las administraciones públicas, de dichos Estados competentes en la materia sobre la que recaiga el tratado. Puede decirse que en estos casos el convenio, celebrado tras una negociación y un acuerdo, da lugar a su vez, durante su ejecución a un continuo proceso de negociación y acuerdo que ya tiene lugar en un nivel administrativo, es decir, entre órganos que carecen de representación para obligar al Estado por medio de tratados internacionales. Estos acuerdos entre los órganos administrativos de las partes que sean competentes por razón de la materia pueden venir previstos en el tratado principal correspondiente, que normalmente designará por su nombre a los órganos que hayan de contratar y delimitará el contenido del futuro acuerdo".

55 Calvo Babío, F., "Naturaleza y alcance...", cit., nota 38, pp. 38 y 39. Este último requisito no ha sido cumplido por varios de los protocolos o acuerdos bilaterales en comento. 
mencionar a través de la simple credencial del ministerio competente y, en la fase de prestación del consentimiento, podría estimarse implícita o tácitamente comprendida la autorización del acuerdo administrativo en la otorgada en el acuerdo-marco por él desarrollado. ${ }^{56}$

Por último, descartamos la naturaleza jurídica de dichos protocolos o acuerdos, como acuerdos no normativos, invocando sus caracteres al calificarlo, sin intención de someterse al derecho internacional y tampoco al inferirse responsabilidades por incumplimiento e incluso, y más importante, sin voluntad de dar vida a un compromiso real aún con la utilización de fórmulas más ágiles, más prácticas. ${ }^{57}$

Calvo Babío expresa la inquietud acerca de que la solución quizás hubiese consistido en convertir los protocolos en verdaderos convenios bilaterales, suscritos en el ámbito del artículo 39.2 del Convenio de La Haya de 1993, en caso de que se concierten con Estados firmantes del mismo. Tal "reconversión no debería restar de flexibilidad a los instrumentos, puesto que la experiencia del Ministerio de Trabajo y Asuntos Sociales nos revela que no suelen modificarse con frecuencia, máxime si se añade un anexo de modificación flexible para los supuestos más susceptibles de variación". 58

Definitivamente, los acuerdos firmados con Rumania, Perú, Ecuador y Colombia son el medio más idóneo para el establecimiento de una cooperación administrativa que facilita, sin lugar a dudas, la constitución de adopciones internacionales entre los Estados partes. Su naturaleza jurídica no es la de un auténtico acuerdo o tratado internacional, no sólo porque no han sido publicados en el Boletín Oficial del Estado, sino porque de su contenido se puede concluir que es un acuerdo de naturaleza administrativa entre órganos de las administraciones respectivas que prácticamente se limitan a fijar el procedimiento a seguir para la adopción de menores, residentes o nacionales según el caso, con respecto a sus países de origen. ${ }^{59}$

56 Remiro Brótons, A., Derecho internacional público, t. 2: Derecho de los tratados, Madrid, 1987, p. 39.

57 Eisemann, P. M., "Le Gentlemen's Agreement comme source du Droit Internacional”, Journal du Droit International, 1979, núm. 1, pp. 326-348; Remiro Brótons, A., "De los tratados a los acuerdos no normativos...", cit., nota 54, pp. 42 y 43; Calvo Babío, F., "Naturaleza y alcance...", cit., nota 38, p. 463.

58 Calvo Babío, F., Reconocimiento en España..., cit., nota 27, p. 89.

59 Parte de la doctrina que se ha abocado a su estudio, expresa la idea de que los acuerdos con "Rumania, Ecuador, Perú y Colombia, plantean dudas por lo que respecta a su naturaleza jurídica, 
Por otra parte, al desplegar las tres condiciones que demanda el artículo 39.2 del Convenio de La Haya de 1993 para ubicar y calificar a este tipo de acuerdos, siempre posicionándonos en la idea de que el legislador, al redactar el referido artículo, se quiso referir a acuerdos internacionales, tratados internacionales, "tratados sujetos al derecho internacional"; concluimos que tampoco Filipinas y Bolivia cumplen con los mismos en su totalidad y por lo tanto no deben ser contemplados como tratados internacionales. ${ }^{60}$ Así vemos que:

1. Filipinas sí cumple con la condición de ser un acuerdo posterior a la entrada en vigor del Convenio de La Haya de 1993 (al igual que el otro Estado contratante: España); Bolivia no cumple con esta condición porque su acuerdo es anterior a la entrada en vigor del Convenio de La Haya de 1993;

2. Filipinas y Bolivia sí cumplen con el objetivo de favorecer la aplicación del mismo en las relaciones recíprocas;

3. Filipinas y Bolivia no se comprometen a transmitir una copia del acuerdo al depositario del Convenio de La Haya de 1993; tan sólo hablan de su entrada en vigor.

Quizás, sólo el último de los acuerdos firmado con España, el correspondiente a Filipinas, podría cumplir (con voluntad y si interpretamos que junto a su publicación en el Boletín Oficial del Estado, se transmite su depósito) con los requisitos establecidos en el artículo 39.2 del Convenio de La Haya de 1993, ahí no cabría entonces una "reconversión" tal y como expuso Calvo Babío. No obstante, se mantiene la postura de calificarlo no como un auténtico tratado internacional sino como un acuerdo administrativo con todas las consideraciones realizadas más arriba acerca de lo determinante de la "voluntad" para que surta sus efectos y cumpla el fin último: cooperación y protección de menores, como si de un convenio internacional se tratara. ${ }^{61}$

puesto que no parece tratarse de auténticos tratados internacionales, dato que revelaría, por ejemplo, el hecho de que no se publicaran en su día en el Boletín Oficial del Estado, y tampoco parece tratarse de actos no normativos", González Beilfuss, C., "El protocolo de adopción internacional...", cit., nota 34.

60 De lo contrario, tendríamos que determinar su posición con el resto de los tratados vigentes. La doctrina expresa, fundamentalmente, un actitud positiva con respecto al acuerdo de Filipinas y su naturaleza de "tratados sujetos al derecho internacional" y una posición negativa con respecto al acuerdo de Bolivia, al no considerarlo, asimismo, como "tratado sujeto de derecho internacional".

61 Marina Hernando, A., "La adopción internacional...", op. cit., nota 53. 


\section{Comentarios a los acuerdos bilaterales en materia de adopción internacional firmados por España}

Antes de comenzar el análisis o comentarios de los acuerdos bilaterales, tendríamos que realizar una puntualización en torno a lo expresado en el artículo 39.1 del Convenio de La Haya de 1993, en el sentido que el convenio prevé que entre los Estados contratantes pueda continuar aplicándose otros tratados internacionales que contengan disposiciones sobre las materias reguladas, salvo que los Estados vinculados por dichos convenios declaren lo contrario. Según González Beilfuss, ${ }^{62}$ no existe declaración en contra y por lo tanto se permite que se sigan aplicando acuerdos como los firmados con Rumania, Perú, Colombia, Ecuador etcétera. Lo idóneo hubiera sido la conclusión de estos acuerdos una vez ratificado el Convenio de La Haya de 1993 y no a la inversa (caso de Rumania, Perú y Colombia) y si se estimaba conveniente, desplegar entonces un acuerdo especial al amparo del artículo 39.2 del Convenio de La Haya de 1993 alcanzando una serie de ventajas adicionales tales como la obligada cooperación entre los Estados en orden a la asignación de una familia al menor, que en la actualidad, a tenor de los protocolos no queda claro si le corresponde en exclusiva al país de origen y ninguna competencia corresponde al país de recepción, circunstancia ésta insoslayable en el texto del Convenio de La Haya de 1993, ya que el acuerdo de las autoridades centrales en ese ámbito debe ser total para que el procedimiento continúe (artículo 23.1 Convenio de La Haya de 1993). ${ }^{63}$

La cuestión en sí es que el artículo 39.1 del Convenio de La Haya de 1993 no se refiere a este tipo de acuerdos o protocolos. Los acuerdos a los que se refiere son: Convenio sobre Competencia Judicial Internacional, Ley Aplicable y Reconocimiento de Decisiones en Materia de Adopción, hecho en La Haya el 15 de noviembre de 1965; Convenio sobre los Aspectos Civiles de la Sustracción Internacional de Menores, hecho en La Haya el 25 de octubre de 1980 o el Convenio sobre los Conflictos de Leyes en Materia de Adopción de Menores, hecho en La Paz el 24 de mayo de 1984.

La idea de considerar sólo los convenios enumerados se debió a la previsión de que éstos presentaban un mayor potencial de conflictos, de-

63 Herrán, A. I., Adopción internacional, Madrid, Dykinson, 2000, p. 23. 
jando de lado otros convenios respecto a los cuales el potencial de conflictos parecía menor. Así, de esta manera, los conflictos que surgieran en relación de los convenios no mencionados habrían de ser resueltos por los Estados contratantes de acuerdo con las normas, si las hubiera, establecidas en estos otros convenios o conforme a las reglas generales del derecho de los tratados.

Por lo tanto, aclarado lo anterior, el primer párrafo, del artículo 39 del Convenio de La Haya de 1993, tiene en cuenta la situación de Estados ya vinculados por tratados en materia de adopción y reproduce la solución clásica, como por ejemplo ocurre con el Convenio de La Haya de 1988 sobre la ley aplicable en materia de sucesiones por causa de muerte; por otro lado, el segundo párrafo, del mismo precepto, admite la posibilidad de que se concluyan acuerdos futuros, no complementarios, que favorezcan su aplicación en las relaciones recíprocas. ${ }^{64}$

En los acuerdos siguientes que serán objeto del análisis se establecen las líneas de cooperación o coordinación entre las diferentes autoridades competentes en materia de adopción internacional para establecer los cauces legales y las garantías jurídicas oportunas y así facilitar los trámites de las adopciones internacionales entre residentes de los citados países. ${ }^{65}$

Una vez realizada la aclaración, quisiéramos adelantar, por otro lado, algunos comentarios que se reafirmarán con el análisis de esta práctica convencional; así tenemos que cada uno de los acuerdos que aquí se comentan tiene una denominación diferente; no ha habido unanimidad a la hora de darles un título que unifique y armonice, en este sentido, la materia objeto de regulación. Así, Rumania, Ecuador, Perú y Filipinas optaron por denominarlos protocolos; Colombia lo denominó acuerdo interinstitucional ${ }^{66}$ y Bolivia lo llamó acuerdo bilateral.

Nosotros en sintonía con la nomenclatura utilizada en el artículo 39.2 del Convenio de La Haya de 1993, creímos conveniente denominarlos

64 Informe Explicativo Parra-Aranguren..., cit., nota 41, pp. 129-131.

65 Herrán, I., op. cit., nota 63, pp. 20-23.

66 González Beilfuss, C., "La aplicación en España...", cit., nota 24, p. 38, los denomina, asimismo, acuerdos interinstitucionales. Esquivias Jaramillo los denomina acuerdos interestatales y expresa que son un "complemento específico al Convenio de La Haya de 1993 que están dotados de su mismo espíritu y su razón de ser, y porque sus consideraciones no son tan desiguales". Esquivias Jaramillo, J. I., Adopción internacional, Madrid, Colex, 1998, p. 25. 
acuerdos, independientemente de la naturaleza jurídica que posea cada uno de ellos tal y como acabamos de exponer.

Por otra parte, tenemos que los acuerdos de Rumania, Ecuador, Perú y Colombia han sido rubricados, por parte de España, por las autoridades ministeriales y más concretamente, por el Ministerio de Trabajo y Asuntos Sociales; y con respecto a las otras partes contratantes, la firma les ha correspondido a los representantes de los organismos que se ocupan en dichos países de gestionar las adopciones internacionales. En los dos acuerdos más recientes hubo un cambio en su rúbrica, a Bolivia le correspondió, por España, al secretario de Estado para la Cooperación Internacional y para Iberoamérica, y por Bolivia, al Ministerio de Relaciones y Culto. Con respecto a Filipinas, firmaron por España, el secretario de Estado de Asuntos Exteriores y por Filipinas, la viceministro de Bienestar y Desarrollo Social.

Por último, hago la observación que de cada uno de los acuerdos o protocolos enunciados se realizarán los comentarios más trascendentes (en el que no podemos evitar las referencias constantes sobre la interpretación que lleva implícita el artículo 17 c) del Convenio de La Haya de 1993), sin necesidad de comentar uno a uno la totalidad de sus artículos ya que son, prácticamente, copia fiel unos de otros, y como siempre suele ocurrir, los últimos, los más modernos, presentan normalmente una técnica jurídica más depurada y una mejor redacción, ya que se retroalimentaron de todas las "incidencias" por las que pasaron los más antiguos, aquellos que se aventuraron a iniciar una obra de tal magnitud. No obstante, pensamos que será pertinente comenzar haciendo un comentario más detallado de los primeros acuerdos firmados: Rumania, dada su particularidad, no sabemos si por su condición de país de la Europa del Este pero que presenta importantes diferencias con los suscritos posteriormente; y Perú por ser, prácticamente, el primero en desplegar todo un articulado ex profeso en torno a la adopción internacional con España, y por último, finalizar con un comentario, igualmente detallado, de los acuerdos más recientes, Bolivia y Filipinas. 
A. Rumania. Protocolo entre el Comité Rumano de Adopciones y el Ministerio de Asuntos Sociales de España para la coordinación de las adopciones internacionales entre Rumania y España, de 2 de abril de 1993

Los datos más recientes que reflejan el número de menores rumanos que llegaron a España son los siguientes: en 1997, 0; en 1998, 84; en 1999, 280; en 2000, 583 y en 2001, 373. Si hacemos referencia al dato que del total de niños recibidos de la Europa del Este, Rumania ocupa el segundo lugar, sensiblemente por debajo de Rusia, se constata que con el paso de los años, un convenio como el que comentamos tuvo realmente efectividad. ${ }^{67}$

En el ámbito de aplicación material, el Protocolo de Rumania de 1993 se refiere, exclusivamente, a las adopciones de menores rumanos por nacionales españoles o ciudadanos rumanos residentes en España. Como diría Esplugues Mota, se trata de un texto que tiene por objeto canalizar la "exportación" de menores rumanos a España. ${ }^{68}$

En el protocolo rumano de 1993 se aborda de forma directa la problemática que plantea la adopción de menores rumanos por españoles o por rumanos residentes en España. ${ }^{69} \mathrm{El}$ protocolo rumano en doce párrafos y un anexo relativo al procedimiento y requisitos para la adopción de niños rumanos, expresa los principios generales que deben permear la coordinación de las adopciones internacionales entre Rumania y España, de acuerdo a la Convención de Naciones Unidas sobre los Derechos del Niño de 1989 y así se enuncia: principio de subsidiariedad, interés superior del menor, garantía de gozar de los derechos, salvaguardas y condiciones equivalentes a las que ya existan en el caso de adopción nacional

67 Orejudo Prieto de los Mozos, P., "El certificado de idoneidad de los adoptantes en el marco de la prevención del tráfico internacional de menores (con especial referencia a las adopciones rumanas)", Aranzadi Civil, núm. 12, octubre de 1998, pp. 20 y ss.; López Orellana, I., "La adopción internacional", $R G D$, julio-agosto de 1996, pp. 8036-8038; Zugravescu, A. et al., "La adopción internacional en Rumania", Infancia y Sociedad. Revista de Estudios, Ministerio de Asuntos Sociales, noviembre-diciembre de 1991, núm. 12, pp. 111 y 122, en donde los autores narran los sucesos inmediatos a la caída de Ceaucescu, tales como la "liberalización" de la adopción internacional, lo cual provocó un inminente tráfico de menores $(10,000$ menores rumanos salieron entre el 1o. de agosto de 1990 y el 17 de julio de 1991), p. 113; acerca del posterior desarrollo legislativo y las funciones del Comité Rumano de Adopciones Internacionales, véase la p. 120.

68 Esplugues Mota, C., "Conclusión por parte de España...", cit., nota 38, p. 337.

69 Herrán, A. I., op. cit., nota 63, p. 21. 
y el principio de no producir, la adopción internacional, ningún beneficio económico indebido.

En cuanto a las "líneas directivas para la coordinación de la adopción”, estipula, literalmente, lo siguiente:

1. La Dirección General de Protección Jurídica del Menor (hoy Dirección General de Acción Social del Menor y de la Familia del Ministerio de Trabajo y Asuntos Sociales) sólo trabajará con el Comité Rumano de Adopciones ${ }^{70}$ para la coordinación de las adopciones internacionales de niños rumanos por nacionales españoles (al menos uno de los dos padres deberá ser de nacionalidad española) y/o por ciudadanos rumanos residentes en España. En consecuencia, el Comité Rumano de Adopciones sólo aceptará las solicitudes de nacionales españoles y de ciudadanos rumanos residentes en España remitidos por la Dirección General de Protección Jurídica del Menor (DGPJM), es decir, no reconocerá, en principio, salvo comunicación en contrario del gobierno español, otra autoridad que la DGPJM.

2. Se exige la constitución de la adopción en el extranjero, en Rumania, por la autoridades competentes, así se expresa que las adopciones de niños rumanos se efectuarán ante la competente autoridad rumana de acuerdo con las leyes rumanas y españolas aplicables.

3. La DGPJM sólo presentará las solicitudes remitidas por los servicios competentes en materia de protección de menores de las Comunidades Autónomas. Esto puede indicar que no se aceptan las adopciones privadas ${ }^{71}$ por parte del Comité Rumano de Adopciones, solamente darán curso a las adopciones independientes, ${ }^{72}$ siempre atendidas por la DGPJM, y a las adopciones tramitadas a través de ECAI, debidamente acreditadas por ambos Estados parte.

4. En el supuesto de que exista alguna excepción a lo dispuesto en el inciso anterior, el Ministerio comunicará al Comité Rumano de Adopcio-

70 Sobre la tramitación de las adopciones internacionales a través del Comité Rumano de Adopciones, véase Orejudo Prieto de los Mozos, P., op. cit., nota 67, pp. 21 y 22.

71 La doctrina, cuando utiliza el término "privado", siempre tiene en mente aquellas adopciones que llevan implícito algún ilícito.

72 Asimismo, la doctrina entiende por adopciones independientes aquellas que los particulares tramitan sin la intervención de una Entidad Colaboradora de Adopción Internacional, ECAI, pero siempre de la mano de la administración, de la autoridad central de su país de residencia; la cual tramita su certificado de idoneidad y le proporciona la información que posee en cuanto a requisitos exigidos en el Estado de origen elegido por los solicitantes. 
nes qué otra autoridad del Estado español puede tramitar directamente las solicitudes de adopción ante dicho comité.

5. El protocolo también enuncia, en anexo, tanto los requisitos como el procedimiento para la adopción de un niño rumano, sin embargo no se especifica nada en relación a la forma prevista para actualizar los requisitos y los documentos exigidos, y así dar eficiencia, agilidad y transparencia al proceso, actualización que se puede realizar por ejemplo a través de canje de notas. En el apartado de requisitos se hace referencia a los candidatos admisibles para la adopción y los niños adoptables; en el apartado referente al procedimiento a seguir para la constitución de la adopción, se especifica la aplicación y documentos requeridos, referencias sobre el niño, aceptación del niño y otros.

En cada uno de estos epígrafes se respeta la práctica internacional en cuanto al listado de los documentos normalmente exigidos, todos ellos debidamente traducidos por traductor jurado, legalizados y autentificados; asimismo también se enumeran los subsecuentes pasos a seguir en el procedimiento de adopción de un niño rumano, ${ }^{73}$ por españoles o por rumanos residentes en España, destacando el envío del informe de preasignación y solicitando la declaración de aceptación entre autoridades centrales y la obligación de desplazarse a los candidatos a Rumania para "finalizar" el proceso de adopción en los noventa días siguientes a la firma de su declaración de aceptación de la adopción. También se hace referencia a los informes de seguimiento pero de manera cuasi informal ya que expresa que "la administración competente en España, facilitará al Comité Rumano de Adopciones informes de seguimiento de la situación de los niños rumanos durante dos años" y subrayamos "facilitará" porque no es lo mismo que solicitar expresamente.

En el apartado titulado "Otros", se mencionan cuestiones de máximo interés ya que el Comité Rumano de Adopciones entrega a la familia un certificado de que el menor no pudo ser colocado o adoptado en Rumania en los seis meses siguientes de su registro en el Comité Rumano de Adopciones, amén de entregar también el resto de documentos que le corresponde al mismo comité. Los gastos de honorarios del abogado privado correran a cargo de los candidatos y serán directamente ingresados en el Banco Rumano de Comercio Exterior. Por último, mencionar las cláu-

73 No olvidemos que es un acuerdo bilateral concebido para la adopción de niños rumanos, concibiendo sólo a Rumania como Estado de emisión de menores. 
sulas de protección del menor en caso de rechazo o abandono en España y los sistemas de cooperación entre ambos países. ${ }^{74}$

A partir de 2002, se cerraron las fronteras en Rumania, en cuanto a la adopción internacional se refiere, debido a un cambio de legislación.

Hoy el protocolo que comentamos se encuentra en un periodo de revisión importante, de hecho ha dejado de estar vigente sin previa renuncia ya que con la ratificación de España ${ }^{75}$ y Rumania ${ }^{76}$ del Convenio de La Haya de 1993, parte de los contenidos enunciados en el protocolo van en contra, explícitamente, con preceptos del Convenio de La Haya de 1993 por lo que será preciso asentar las bases del protocolo con Rumania sobre las normas y previsiones del citado convenio. ${ }^{77}$

Las circunstancias actuales de Rumania, el descrédito internacional hacia su concepción de las políticas de protección a la infancia no influye positivamente en su "reaparición" en el panorama de la adopción internacional.

B. Perú. Protocolo entre el Ministerio de Asuntos

Sociales de España y el Ministerio de la Presidencia

del Perú en Materia de Adopción Internacional,

hecho en Madrid, a 21 de noviembre de 1994

Los datos que disponemos en relación a menores peruanos adoptados por residentes españoles son: en 1997, 81; en 1998, 151; en 1999, 126; en 2000,99 y en 2001,71 .

El protocolo consta de una Exposición de motivos, cuatro títulos, quince artículos y un anexo.

En el título I “Ámbito de aplicación” (artículos 1-2), comienza, el protocolo peruano, en su artículo 1 por instaurar un sistema de cooperación entre las partes que asegure, en los procesos de adopción, la total eliminación y la prevención de la sustracción, tráfico, trata y venta de

74 Destacar que existe en la actualidad un convenio entre España y Rumania complementario del convenio relativo al procedimiento civil concluido en La Haya el 1o. de marzo de 1954, hecho ad referéndum en Bucarest el 17 de noviembre de 1997, con entrada en vigor el 10 de febrero de 1999, que facilita la notificación de documentos y la ejecución de comisiones rogatorias en materia civil y mercantil entre ambos Estados contratantes.

75 España ratifica el 11 de julio de 1995; con entrada en vigor el 1o. de noviembre de 1995.

76 Rumania ratifica el 28 de diciembre de 1994, con entrada en vigor el 1o. de mayo de 1995.

77 Como ejemplo de esto, tenemos que el Convenio de La Haya de 1993 contempla, en el ámbito espacial, la posibilidad de la constitución de la adopción tanto en el país de origen como en el de recepción. El Protocolo de Rumania contraviene este precepto de la convención. 
menores de edad. En el segundo inciso, se expresa el asegurar el reconocimiento recíproco de las adopciones plenas efectuadas según el protocolo, constituidas de acuerdo con las legislaciones de ambos Estados. ${ }^{78}$

El artículo 2 ya expresa, en el inciso primero, el ámbito de aplicación territorial al referirse que el acuerdo o protocolo es aplicable en el caso de un menor de edad español o peruano para que sea adoptado plenamente por nacionales del otro Estado; es decir se recoge el supuesto de nacionales y no se contempla, como es ya lo habitual atendiendo al concepto de adopción internacional estipulado en el artículo 2 del Convenio de La Haya de $1993,{ }^{79}$ el concepto de residencia "habitual".

Por otro lado, se continúa y se recoge un supuesto que, hasta la fecha, no se había plasmado en un texto de similares características, como es aplicar el acuerdo también a los menores apátridas que se encuentran en el territorio de uno de los dos Estados, para su adopción por nacionales del otro Estado. El hecho, definitivamente, es altamente improbable en referencia a menores apátridas que se encuentren en territorio peruano o español, ${ }^{80}$ dados los supuestos en los que se encuadra a un individuo

78 Tanto en el protocolo de Perú, que comentamos, como en el siguiente, el de Colombia, se expresan las mismas ideas no sólo en este primer título sino en los tres restantes, de hecho, muchas de las referencias se repetirán a veces, y otras las daremos por comentadas para no reiterar.

79 El artículo 2, párrafo primero, del Convenio de La Haya de 1993, se expresa, en relación a la adopción internacional, de la siguiente manera: "1. La convención se aplica cuando un niño con residencia habitual en un Estado contratante ("el Estado de origen") ha sido, es o va a ser desplazado a otro Estado contratante ("el Estado de recepción"), bien después de su adopción en el Estado de origen por cónyuges o por una persona con residencia habitual en el Estado de recepción o en el Estado de origen". De esta manera se pronuncia una doctrina mayoritaria que entiende por adopción internacional el acto jurídico que celebran personas con residencia habitual fuera del territorio nacional, independientemente de que sean ciudadanos de otro país o no. Bastará que tenga su residencia habitual fuera del territorio nacional para que se considere adopción internacional. Hay autores que contemplan los diferentes elementos internacionales (nacionalidad, ciudadanía, residencia, etcétera) que pueden estar aparejados a la adopción internacional para calificarla o no como tal; a modo de ejemplo, Bouza Vidal, N., "La nueva Ley 21/1987, de 11 de noviembre, sobre adopción y su proyección en el derecho internacional privado", $R G L J, 1987$, t. II, p. 921, contabiliza hasta catorce supuestos distintos de adopción internacional autorizados por la autoridad en España, tomando en cuenta, como elementos internacionales que le dan el carácter de extranjero, sólo la nacionalidad y residencia de adoptante y adoptado.

80 La posibilidad no sería tan descabellada si estuviéramos hablando de menores procedentes del ex Sahara occidental español o menores palestinos. El problema real que se da, cuando hablamos de estos menores en esta situación de apatridia, es solventar la cuestión acerca de cuál es la ley aplicable a la hora de constituir su adopción, atendiendo al interés superior del mismo. Calvo Caravaca opina que no procede aplicar la ley nacional del menor, porque éste carece de nacionalidad y se desvanece así el interés de que la adopción sea válida en el país cuya nacionalidad ostenta el menor. Id, "Globalización y adopción internacional", en Calvo Caravaca, A. L. y Blanco-Morales 
como tal, como apátrida, sin nacionalidad ${ }^{81}$ pero es importante y plausible la inclinación de recoger dicho supuesto si lo queremos ver como una protección más al interés superior del menor.

En el artículo 2, inciso segundo, se define lo que ha de entenderse por "menor de edad", a la persona menor de dieciocho años, cuestión que debiera definirse o estipularse, precisamente en la parte expositiva del protocolo, cuando se refieren a principios generales y no en este apartado dejando sin cubrir lo referente al ámbito de aplicación material.

El título II "Autoridades Centrales y organismos autorizados" (artículos 3-6), remite con respecto a las autoridades centrales, en su artículo 3 , inciso primero, al listado de instituciones que aparecen relacionadas en el anexo I, coincidente, a su vez, con el incluido en la declaración formulada por España al ratificar el Convenio de La Haya de 1993; es decir, enuncia una autoridad central de comunicación que es el Ministerio de Trabajo y Asuntos Sociales, a través de su Dirección General de Protección Jurídica del Menor y en este caso, la que hace las veces de esta dirección en el momento actual, Dirección General de Acción Social, del Menor y de la Familia, así como una autoridad central por cada una de las Comunidades Autónomas con respecto a su territorio y sus residentes.

Por lo que respecta a Perú, se limita a estipular que su autoridad central es la Secretaría Técnica de Adopciones.

Se prevé también la posibilidad de que cuando se produzca alguna excepción a lo expuesto, en cuanto a las autoridades centrales, se posibilite la actuación directa ante la Secretaría Técnica de Adopciones de alguna o algunas Comunidades Autónomas, así el Ministerio español comunicará a la Secretaría Técnica de Adopciones de Perú qué comunidad o Comunidades Autónomas pueden tramitar directamente las solicitudes de adopción y efectuar también directamente las demás comunicaciones que se indican a lo largo del protocolo.

Limones, P. (coords.), Globalización..., cit., nota 1, p. 31. Quizás la solución más lógica y viable sea aplicar, en este caso, la ley nacional del Estado de recepción del menor.

81 Los casos de apátridas son principalmente individuos nómadas; individuos hijos de apátridas natos; individuos que se fijan sobre un territorio sin que la ley del lugar les absorba cuando menos durante un tiempo razonable; e individuos que han perdido su nacionalidad, sea a título de voluntad (como, por ejemplo, matrimonio con extranjero en algunos países), o a título de pena (individuos que incurren en alguna de las causas que en su país traen consigo la pérdida de la nacionalidad sin que hayan adquirido otra). González Martín, N., Régimen jurídico de la nacionalidad en México, México, UNAM, Instituto Investigaciones Jurídicas, 1999, Cuadernos Constitucionales México-Centroamérica, núm. 33, pp. 81 y 82. 
En el artículo 3, inciso segundo, se refiere a la delegación de funciones por parte de las autoridades centrales a organismos públicos o privados, debidamente autorizados por la parte que propone y aceptados por la otra parte; ${ }^{82}$ hace referencia a la viabilidad de constituir mediación a través de Entidades Colaboradoras de Adopción Internacional, ECAI, con la percepción de la doble acreditación, es decir, autorizados por España y aceptados por Perú. El siguiente inciso tercero hace referencia al control, vigilancia y sistema de sanciones que se les da a estos organismos por parte de la autoridad central del Estado de recepción.

El artículo 4, inciso primero, en línea con lo dispuesto en el artículo 7, inciso 1, del Convenio de La Haya de 1993, especifica que "promoverán la colaboración de las autoridades competentes de ambos Estados para asegurar la protección de los menores de edad adoptables y lograr los otros objetivos del protocolo; en particular, estas efectuarán y seguirán, de acuerdo entre ellas, la fase preadoptiva, que consistirá en la designación de un menor de edad adoptable a las personas consideradas más idóneas para adoptarlo y vigilarán la fase posterior a la resolución judicial".

Parece expresar el mencionado artículo, de un "plumazo" —cuestión que no nos parece la más adecuada-, el procedimiento y fases más significativas de la adopción internacional, eso sí, reforzando la importancia que se le da a la fase preadoptiva con la preasignación o colocación de un menor, así como la selección de aquellos solicitantes más aptos o idóneos para el menor. ${ }^{83}$

Igualmente, a tenor del artículo 4, inciso segundo, deberán informarse, recíprocamente, sobre sus legislaciones nacionales en materia de adopción y sobre cualquier otro asunto de carácter general referente a la adopción, y mantendrán constantemente contactos en relación con el

82 El Convenio de La Haya de 1993 expresa que son funciones indelegables de las autoridades centrales: 1. La cooperación y promover la colaboración (artículo 7. 1 Convenio de La Haya de 1993); 2. Medidas necesarias para propiciar la información sobre sus respectivas legislaciones aplicables (artículo 7. 2 Convenio de La Haya de 1993); 3. Recibir informaciones procedentes del personal que interviene en la adopción (artículo 33 del Convenio de La Haya de 1993). Asimismo, el propio convenio enumera otro tipo de funciones que sí son susceptibles de delegar las autoridades centrales, como pueden ser las medidas sobre el control de los beneficios materiales indebidos (artículo 8 del Convenio de La Haya de 1993) o aquellas otras relativas a la recepción de la solicitud de adopción internacional (artículo 14, en relación con el artículo 22.1 Convenio de La Haya de 1993) entre otras. Véase en torno al tema a Carrillo Carrillo, B. L., Adopción internacional..., cit., nota 28 , pp. 87-91.

83 Véase lo comentado con respecto a su artículo 60. 
funcionamiento del protocolo y procederán a eliminar los obstáculos que pudieran impedir su realización.

El artículo 5 incide en lo estipulado en los artículos 8 y 9 del Convenio de La Haya de 1993 y así expresa que las autoridades centrales, directamente o a través de los organismos autorizados, tomarán medidas apropiadas que aseguren la primacía del interés superior del menor; facilitar, seguir y activar el proceso de adopción; impedir la obtención de beneficios indebidos en la adopción, realizar y promover el control en materia de adopciones en los Estados respectivos, así como proporcionarse elementos de evaluación con relación a las adopciones internacionales efectuadas de acuerdo al presente protocolo; de hecho, hace referencia expresa a los informes de seguimiento que tendrán una periodicidad semestral durante cuatro años. Es importante destacar que el hecho de que en un protocolo de estas características se estipule, expresamente, esta información postadoptiva va en sintonía con el espíritu del Convenio de La Haya de 1993.

El artículo 6, por su parte, determina en qué momento se considera que tienen lugar las adopciones consideradas en el protocolo. En este sentido, exige que se reúnan determinados requisitos, similares a los previstos en los artículos 4 y 5 del Convenio de La Haya de 1993:

1. La autoridad competente haya declarado al menor de edad en estado de abandono o adoptable;

2. La autoridad central del Estado de origen del menor de edad haya verificado que la adopción internacional responde al interés superior del menor de edad en cuestión;

3. La autoridad central del Estado que recibirá al menor de edad garantice que los futuros adoptantes son declarados aptos para la adopción internacional;

4. El organismo competente del Estado que recibirá al menor de edad garantice que será autorizado a ingresar y residir permanentemente en ese Estado.

5. La autoridad del Estado de origen, de acuerdo a su competencia, haya asignado a los futuros adoptantes al menor de edad.

Obviamente es loable cada uno de los requisitos estipulados, dada la convergencia y coincidencia con el articulado ad hoc del Convenio de La Haya de 1993; pero ponemos en duda la viabilidad o lo acertado de la idea que se expresa en este artículo 6 del protocolo cuando dice que le corresponde al Estado de origen, "de acuerdo a su competencia", asignar 
al menor a los solicitantes y así lo expresa dando la idea de que esta potestad le corresponde sólo al Estado de origen y no la debe compartir con el Estado de recepción; cuestión que va en contra de lo estipulado en el artículo 17 c) del Convenio de La Haya de 1993.

Según el artículo 17 c) del Convenio de La Haya, el Estado de origen sólo podrá confiar al niño a los futuros padres adoptivos siempre y cuando las autoridades centrales de ambos Estados estén de acuerdo. Este inciso c) exige el acuerdo de las autoridades centrales de ambos Estados para que "se siga el procedimiento de adopción" y ello significa que la adopción podrá entrar en la etapa siguiente del procedimiento hacia su finalización. Es un inciso que permite, en un momento dado, a ambos Estados, al Estado de origen y al Estado de recepción, detener una adopción si existen, o pudiera parecer que existen, obstáculos jurídicos importantes. En definitiva, el inciso c) regula implícitamente las condiciones de la adopción ya que si uno de ambos Estados considera que existe un impedimento, la autoridad central del otro Estado tendrá la facultad de denegar su acuerdo a que se siga el procedimiento de adopción. ${ }^{84}$ De ello se desprende esa reiterada necesidad de colocación del menor conjunta. ${ }^{85}$ Ambos Estados deben remitir su anuencia o acuerdo para que dicha colocación sea en interés superior del menor, conforme a derecho y así se prosiga el procedimiento. El artículo 17 c) del Convenio de La Haya de 1993 reviste, como vemos, una gran importancia para el resultado exitoso de la adopción y del Convenio de La Haya en sí.

El título III "Procedimiento" (artículos 7-11), en su artículo 7, inciso primero, en consonancia con el contenido del artículo 14 del Convenio de La Haya de 1993, expresa que "los futuros adoptantes, debidamente declarados idóneos, dirigirán la solicitud a la autoridad central del Estado del que son nacionales o a los organismos autorizados", y en su inciso segundo, esta autoridad central u organismo acreditado, que recibirá su solicitud, la remitirá a la autoridad central del otro Estado con toda la información y documentación exigida, en consonancia, una vez más, al artículo 15 del Convenio de La Haya de 1993. Toda la documentación dirigida al Estado de origen deberán estar debidamente legalizada y autentificada, además el Estado de origen deberá acusar de recibo la soli-

84 Informe explicativo de G. Parra-Aranguren, Convenio de 29 de mayo de $1993 \ldots$, op. cit., nota 41, pp. 79 y 80 .

85 Otra cuestión es que los Estados involucrados tengan que dar sus respectivas propuestas y autorizaciones de forma simultánea, cuestión que no se menciona en ningún momento. 
citud y comunicará a la autoridad central del Estado de recepción u organismo autorizado que medie en el expediente, la aceptación o rechazo de la misma.

El artículo 80. se detiene en el que se puede denominar informe de adoptabilidad que debe remitir el Estado de origen cuando prevé que hay una preasignación. De esta manera enuncia que:

La autoridad central del Estado de origen del menor de edad o los organismos autorizados transmitirán a la autoridad central o al organismo autorizado del Estado de recepción todas las informaciones relativas a: edad, sexo, antecedentes sociales, cuando sea posible, informe sobre su estado físico, antecedentes médicos de los progenitores e incluso fotografía reciente del menor.

Todo esto en relación a lo estipulado, asimismo, en el artículo 16 del Convenio de La Haya de 1993.

Posteriormente el protocolo en su artículo 9, parece dar un paso hacia atrás porque después de estipular lo solicitado en una preasignación, estipula que en el momento en que la autoridad central u organismo acreditado acuerden la asignación (o preasignación) de uno o más menores adoptables a los solicitantes, se lo comunicarán a la mayor brevedad posible a la autoridad central u organismo acreditado del otro Estado. Quizás sería más conveniente expresar lo relativo a la aceptación o no de la preasignación para después enumerar la documentación que uno y otro Estado debe tramitar y remitir. Lo importante será, en consecuencia, que en el "espíritu" del legislador se atienda al artículo 17 c) del Convenio de La Haya de 1993, en la decisión conjunta de ambos Estados en la preasignación o asignación del menor. ${ }^{86}$

El mismo artículo, no en este orden señalado, nos sitúa en dos hipótesis:

1. Cuando el menor de edad preasignado es aceptado (no indica el orden necesario de: 1o.) autorización por parte de la autoridad central del Estado de recepción y 2o.) la aceptación de los futuros padres adoptivos), se iniciará (sic se seguirá) el proceso necesario, en el que se firmará una declaración de su intención de adoptar al menor propuesto, en un plazo no superior a quince días desde la recepción de la comunicación.

86 Con posterioridad abordaremos de nuevo este tema al hablar del matching. 
Todo ello se llevará a cabo según las leyes de cada Estado, manteniéndose recíprocamente informados sobre dicho procedimiento y sobre las modalidades actuadas para llevarlo a buen término. En todo caso, para finalizar el proceso de adopción, los solicitantes deberán desplazarse al país de origen del menor de edad en el más breve plazo, que no excederá de treinta días útiles, debiendo permanecer en el país hasta que la adopción haya sido concluida.

Aquí habría que comentar que es conveniente que el tiempo de espera para el menor no se prolongue, con el fin de no crear ansiedades o dudas al menor con respecto a la llegada de su nueva familia; pero por el contrario es un espacio breve para los solicitantes que deben proyectar un viaje. No se expresa el tiempo que durará el proceso y por consiguiente su estancia en Perú, pero ello no exenta la necesidad de notificar su ausencia con suficiente antelación a sus lugares de trabajo, eso sin especificar si hay responsabilidades familiares, hijos biológicos por ejemplo, que también deberán dejar debidamente atendidos.

2. Si el menor de edad no es aceptado, los solicitantes deberán manifestarlo por escrito en un plazo no superior a quince días desde la recepción de la comunicación.

Por otra parte, igualmente con respecto al procedimiento, en el artículo 10 se especifica que la autoridad central del Estado que recibe al menor de edad, garantizará, de acuerdo con su legislación, el cumplimiento de todas las acciones necesarias para el reconocimiento de la adopción plena e informará a la autoridad central del Estado de origen del menor de edad remitiendo la documentación pertinente; un tema de máximo interés considerando toda la trayectoria que ha tenido el reconocimiento de las adopciones internacionales. ${ }^{87}$

No encuadraríamos precisamente este precepto en el rubro de procedimientos, más bien lo incluiríamos, tal y como hace el artículo 7 del Protocolo de Filipinas que analizaremos en breve, en un artículo anterior al título de procedimientos, con la indicación expresa de "garantizar el

87 Al respecto, sugerimos la lectura de Calvo Babío, F., Reconocimiento en España ... cit., nota 27; Carrillo Carrillo, B. L., Adopción internacional..., cit., nota 28; García Cano, S., Protección del menor y cooperación internacional entre autoridades, Madrid, Colex, 2003; Rodríguez Benot, A., "El reconocimiento de las medidas de protección del menor en un entorno multicultural (un estudio comparado de la eficacia extraterritorial de la adopción y de la kafala)", $R G D$, núm. 667, abril de 2000, pp. 4419-4447; id., "La eficacia extraterritorial de la adopción simple (el reconocimiento en España de las adopciones simples constituidas al amparo de ordenamientos iberoamericanos)", en González Martín, N. y Rodríguez Benot, A. (coords.), op. cit., nota 6, pp. 365-389. 
cumplimiento de todos los requisitos necesarios para el reconocimiento de la plena adopción, informando de ello a la autoridad central del Estado de origen, enviándole la documentación pertinente".

Asimismo, en el procedimiento de una adopción de un menor peruano, el artículo 11 expresa que en caso de que en el curso del proceso de adopción (sin especificar la fase del proceso — previa o intermedia-) se verifiquen impedimentos tales que, considerando el interés superior del menor de edad, hacen no oportuno el reconocimiento de la adopción, la autoridad central que constante tal impedimento informará inmediatamente a la autoridad central del otro Estado, para establecer, de común acuerdo, las medidas más apropiadas para salvaguardar los derechos del menor de edad. Durante este periodo la autoridad central asegurará la plena protección del menor de edad hasta que se acuerde la medida de protección definitiva. ${ }^{88}$

Este tipo de "impedimentos" expresado en este artículo es difícil de concebir si, realmente, se hizo con el cuidado debido la preasignación o asignación del menor. Pensamos en el supuesto de que se superó el consenso o acuerdo de asignación, según el artículo 17 c) del Convenio de La Haya de 1993, por lo tanto no debe de referirse a impedimentos jurídicos sino a cuestiones sobrevenidas de la convivencia del menor con sus futuros padres adoptivos y la constatación de que no hay empatía entre menor y solicitantes. ${ }^{89}$

En el título IV “Cláusulas finales” (artículos 12-15), en el artículo 12 , se compele a las autoridades centrales a conservar toda la información relativa a los orígenes del menor y su familia, si fueren conocidas, y a permitir el acceso a la misma, con las autorizaciones necesarias, dentro de los límites establecidos por las leyes de los Estados que concluyen el protocolo; así como, en el artículo 13, a velar por que se respeten las disposiciones contenidas en los mismos.

El artículo 14 atribuye una duración indefinida a los protocolos, que puede ser modificada en todo momento a través de acuerdo escrito de las partes firmantes, así como la denuncia unilateral por parte del Ministerio de Trabajo y Asuntos Sociales español o por el Ministerio de la Presiden-

88 Herrán, A. I., op. cit., nota 63, p. 23.

89 De hecho, en muchos países de origen se estipula, dentro de su procedimiento, que haya una etapa de convivencia previa al inicio del proceso judicial, no inferior a una semana ni superior a dos en el caso mexicano, en el que se podría facilitar la adaptación del menor y sus futuros padres adoptivos, y por tanto darse la empatía entre ellos. 
cia peruana, previa notificación escrita a la otra parte. Esta notificación producirá efectos a los tres meses. La denuncia del protocolo no tendrá ningún efecto sobre la tramitación de las adopciones ya iniciadas hasta que quede ultimado todo el proceso, ni sobre los compromisos adquiridos en relación a los menores de edad ya adoptados.

El artículo 15, por último, incorpora, al decir de Esplugues Mota, "una misteriosa llamada final a la no aplicación de los protocolos 'a las adopciones en los casos de excepción o particulares contemplados en la legislación de cada Estado". ${ }^{90}$

La duda que nos queda al final de la lectura de este protocolo peruano es lo "oculto" del mismo, ya que no se publica, no sólo en el Boletín Oficial del Estado sino tampoco en ningún otro lugar accesible a los interesados.

\section{Colombia. Acuerdo interinstitucional}

entre el Ministerio de Asuntos Sociales de España

y el Instituto Colombiano de Bienestar Familiar

en Materia de Adopción, hecho en Madrid,

a 13 de noviembre de 1995

Este acuerdo pretende hacer frente a una realidad muy consolidada, en el sentido de que Colombia representa uno de los países con más volumen de emisión de menores en adopción internacional. ${ }^{91}$ España recibió en 1997, un total de 250 menores colombianos; en 1998, 393; en 1999, 361; en 2000, 414 y en 2001, 319. Estas cifras representan cada año, en torno al $40 \%$ de los menores latinoamericanos que llegan a España. Con estos datos, necesariamente se justifica que ambos Estados, de origen y de recepción, buscaran, en su momento, un mecanismo en forma de acuerdo, para facilitar y garantizar la transparencia de las adopciones entre ambos países.

El acuerdo interinstitucional firmado con Colombia consta de cuatro títulos, entre los que se distribuyen quince artículos y un anexo.

El acuerdo comienza, al igual que sus antecesores, con un enunciado de derecho o principios generales sobre la protección de menores, siem-

90 Esplugues Mota, C., “Conclusión por parte de España...”, cit., nota 38, p. 340.

91 López Orellana, I., op. cit., nota 67, pp. 8027-8067; Lozano Pinto, Y., "La nueva regulación de la adopción en el derecho colombiano", Anuario de Derecho Civil, 1996, vol. III, t. XLIX, pp. 1183-1189. 
pre con un objetivo doble: por un lado, evitar situaciones abusivas en relación a los menores, tales como sustracción, tráfico o trata de menores; y por otro lado, procurar el pleno reconocimiento recíproco de las adopciones plenas efectuadas y constituidas entre los países que han suscrito el protocolo. ${ }^{92}$

El artículo 2 en su inciso primero, se refiere a la aplicación del acuerdo de "menor de edad residente en España o Colombia para que sea adoptado plenamente como residentes en el otro Estado". Tanto los menores como los solicitantes deben ser residentes, que no nacionales, de los Estados parte, tratando de ir en sintonía con lo estipulado en el Convenio de La Haya de 1993, pero aún le faltó, al acuerdo colombiano, la partícula de residente "habitual", como expresa el artículo 2 del Convenio de La Haya de 1993. En el mismo artículo se refiere Colombia a la adopción plena. ${ }^{93}$

Los sucesivos artículos reiteran las precisiones estipuladas en el protocolo de Perú, tales como qué debe entenderse por menor de edad, ${ }^{94}$ designación de autoridades centrales (por parte de España las mismas relacionadas en el acuerdo peruano y con respecto a Colombia, el Instituto Colombiano de Bienestar Familiar, ICBF), delegación en organismos públicos o privados acreditados y autorizados por ambos Estados parte, y así sucesivamente, por lo que no vemos la necesidad de reiterar los comentarios ya efectuados en sintonía con el acuerdo peruano. Sólo expresar que se mantienen criterios coincidentes siempre con el Convenio de La Haya de 1993.

El artículo 7 expresa, en cuanto al procedimiento, lo estipulado en el mismo artículo e inciso del Protocolo de Perú salvo que no exige acuse de recibo de la solicitud remitida al Estado de origen. No olvidemos que el procedimiento tiene su fundamento en el intercambio de comunicaciones o informes de control entre las autoridades, y así garantizar el buen

92 Herrán, A. I., op. cit., nota 63, p. 22.

93 El Convenio de La Haya de 1993 se aplica también a adopciones simples o menos plenas, es decir, adopciones que no suponen la ruptura de vínculos entre el adoptando y su familia de origen. Ambas adopciones, al igual que la plena, supone, como decimos, el establecimiento de un vínculo de filiación. No se debe limitar la aplicación del Convenio de La Haya de 1993 a las adopciones plenas. Calvo Caravaca, A. L., "Globalización y adopción...", en Calvo Caravaca, A. L. y Blanco-Morales Limones, P. (coords.), Globalización ... op. cit., nota 1, p. 48.

94 Menores de dieciocho años, siguiendo, una vez más, las prescripciones del Convenio de La Haya de 1993. 
fin del procedimiento, por lo tanto Colombia deja sin cubrir ciertos requisitos de esta índole.

El artículo 9 rectifica las apreciaciones a las que hacíamos referencia con respecto al artículo 6 del protocolo peruano y así expresa que las:

Autoridades Centrales o los organismos autorizados, en el momento que acuerden la designación de uno o más menores de edad adoptables a los solicitantes, iniciarán el proceso necesario, según las leyes de cada Estado, para llegar a la adopción, manteniéndose recíprocamente informados sobre dicho procedimiento y sobre las actuaciones desarrolladas para llevarlo a buen término.

No importa si no se dice nada con respecto a las autorizaciones exigidas para la asignación del menor o la documentación y firmas necesarias para proseguir el proceso debido; lo verdaderamente destacable es el importante paso que da el acuerdo colombiano al contemplar lo estipulado en el artículo 17 c) del Convenio de La Haya de 1993 que, como decíamos, asegura que la decisión de atribución de un niño a unos concretos solicitantes será una decisión conjunta del Estado de origen y del Estado de recepción, como un punto clave de la convención; ${ }^{95}$ se trata de un acuerdo conjunto para que la adopción pueda entrar en la etapa siguiente del procedimiento hacia su finalización.

En cambio, el artículo 11 del protocolo colombiano, va más allá de lo estipulado, por ejemplo, en el protocolo peruano cuando expresa que:

En el caso que en el curso del proceso de adopción se verifiquen impedimentos, "o inhabilidades o su equivalencia en derecho colombiano y español" tales que, considerando el interés superior del menor de edad, no hacen oportuno el reconocimiento de la adopción, la autoridad central que constata tales impedimentos o inhabilidades informará inmediatamente a la autoridad central del otro Estado, para establecer de común acuerdo las medidas más apropiadas para salvaguardar los derechos del menor de edad. Durante este periodo la autoridad central asegurará la plena protección del menor de edad hasta que se acuerde la medida de protección definitiva.

95 No se deja "al arbitrio exclusivo de las autoridades competentes del Estado de origen la fase más crucial del procedimiento de adopción", cuestión que lamentaba González Beilfuss, C., en "La aplicación en España...", cit., nota 24, p. 39. 
Lamentamos la inclusión de este tipo de coletilla, tal y como pusimos de manifiesto en el comentario peruano, ya que tienen muchas implicaciones de falta del debido cuidado en la etapa previa de preasignación, no obstante, el añadido de "o inhabilidades o su equivalente en derecho colombiano y español" parecer querer dejar claro que son sobrevenidas.

D. Ecuador. Protocolo entre el Ministerio de Trabajo y Asuntos Sociales de España y el Ministerio de Bienestar Social de Ecuador en Materia de Adopción Internacional, hecho en Madrid a 18 de marzo de 1997

Los datos de menores ecuatorianos que llegaron a España, vía adopción internacional, fueron: en 1997, 0; en 1998, 3; en 1999, 0; en 2000, 21 y en 2001,16 .

Las cifras aportadas no son denotativas de una afluencia significativa de menores ecuatorianos a España, no obstante, se protocolizó un acuerdo en este sentido, lo cual no desmerece la voluntad e iniciativa de ambos gobiernos.

El protocolo consta de una exposición de motivos, cuatro títulos, catorce artículos y dos anexos, y no difiere, prácticamente, en casi nada de lo que ha sido habitual en sus antecesores.

En él se establece la aplicación del protocolo en el caso de un menor residente en España o en Ecuador para que sea adoptado plenamente por residentes en el otro Estado; aplicándose también a los menores apátridas que se encuentren en el territorio de uno de los dos Estados; también se establecen los trámites a seguir para las adopciones entre ambos Estados y se prevé el cauce de las comunicaciones y actuaciones, que corresponde, por parte de Ecuador, al Departamento Técnico de Adopciones, y por España, a la actual Dirección General del Menor y la Familia, previendo que, en caso de que se realice una comunicación directa entre las autoridades centrales de las Comunidades Autónomas y las del Estado de origen, se proceda a comunicar dicha circunstancia a la Dirección General, luego en el protocolo se concede preferencia en la tramitación y conocimiento de los expedientes a la Dirección General, lo que no excluye la posibilidad de una actuación directa de los demás entes administrativos. ${ }^{96}$ 
En cuanto al tema en el que hemos centrado más nuestros comentarios, referentes a la designación del menor, Ecuador enuncia textualmente lo estipulado en el artículo 9 del acuerdo colombiano, pero lo hace en el anexo II "Requisitos y procedimiento" apartado cuatro relativo a la "Asignación del menor". Se recoge así un precepto que no difiere de lo estipulado en el Convenio de la Haya de 1993.

\section{E. Bolivia. Acuerdo bilateral entre el Reino de España} y la República de Bolivia en materia de adopciones, hecho en Madrid el 29 de octubre de 2001, Boletín Oficial del Estado núm. 304, de 20 de diciembre de 2001

Este acuerdo sustituye a dos anteriores de 5 de abril de 1995 y de 21 de mayo de 1997.

España recibió en 1997, un total de 18 niños bolivianos; en 1998, 31; en 1999, 59; en 2000, 66 y en 2001, 18.

El acuerdo no está dividido en títulos, como ya era la práctica habitual en los anteriores acuerdos y así despliega un "preámbulo", seis artículos y seis disposiciones finales.

El acuerdo comienza por enunciar una serie de principios básicos, principios generales, sin ser propiamente un preámbulo, como es el principio de subsidiariedad establecido en el artículo 21 de la Convención de Naciones Unidas sobre los Derechos del Niño de 1989, en el que ubica a la adopción internacional como un medio de protección a la infancia cuando no encuentra una familia en su país de origen, así como el principio del interés superior del niño como fundamento y base interpretativa del acuerdo bilateral entre España y Bolivia; la salvaguarda del derecho del niño a su identidad cultural y étnica, aunque esta última no lo mencione expresamente; asimismo se aboga, como regla establecida en el mismo preámbulo, que el menor debe tener seguridades equivalentes a aquellas existentes en el caso de adopción nacional; la colocación del menor llevada a cabo por autoridades competentes; que no se genere, a través de la adopción internacional, ningún beneficio indebido para aquellas personas involucradas en el proceso $\mathrm{y}$, por último, se menciona la voluntad de instaurar, a través de un acuerdo como el presente, un sistema de cooperación entre las partes que asegure la prevención y, en su caso, la total eliminación de la sustracción, tráfico y venta de menores. 
El artículo 1, con el título de "Ámbito de aplicación”, establece el mismo al referirse que "constituye el marco para el tratamiento y tramitación de las solicitudes dentro de las normas legales bolivianas y españolas y la conceptualización de la doctrina sobre la institución jurídica de la adopción legalmente reconocida en ambos países", y establece el ámbito territorial al referirse al niño, niña o adolescente (no se determina el concepto de menor o niño) con "residencia habitual en el territorio de la República de Bolivia o en España pueda ser adoptado plenamente por nacionales de uno u otro Estado, de acuerdo con las disposiciones constitucionales y legales vigentes en uno y otro país".

Subrayamos la palabra nacionales porque claramente de este precepto se desprende que sólo es aplicable a las adopciones que se den dentro de este acuerdo entre nacionales de uno u otro Estado. Precepto que difiere, en este caso, del Convenio de La Haya de 1993 que sólo expresa la cuestión de residencia con respecto a los menores y a los solicitantes.

Bolivia, además, al expresar esa condición de nacional para poder ser sujeto de la adopción internacional deja sin contemplar el tratamiento que debe dispensarse, por ejemplo, a los cónyuges de distinta nacionalidad en caso de adopción conjunta.

En los subsecuentes artículos quedan plasmados quiénes serán las autoridades centrales de ambos Estados parte (en Bolivia, el viceministro de Asuntos de Género, Generacionales y Familia, o la institución que por mandato de la ley, asuma en el futuro dichas funciones y responsabilidades, y en España la misma autoridad designada hasta ahora en todos los protocolos anteriores), delegación de funciones a organismos acreditados debidamente autorizados por ambos Estados, requisitos de la adopción, compromiso recíproco de informar sobre sus legislaciones y el procedimiento respectivo.

En cuanto a los requisitos para proceder a la adopción, no existe gran diferencia con respecto a los exigidos en el Convenio de La Haya de 1993, así: a) Declaración del menor en abandono o como adoptable; b) Verificar que la adopción internacional responde al interés del menor; $c$ ) Declaración de idoneidad de los futuros padres para la adopción internacional; d) Garantizar al menor la entrada y la residencia definitiva en el Estado de recepción y e) Que la autoridad central de origen haya asignado al menor a sus futuros padres.

El convenio regula, por otra parte, aspectos de procedimiento de las adopciones internacionales pero no fija la competencia judicial para la 
constitución de las mismas ni criterios sobre la ley aplicable a la adopción internacional. ${ }^{97}$

Otra cuestión que se destaca de la lectura del acuerdo boliviano, es lo expresado en el artículo 4, inciso e, en cuanto a la decisión de colocación del niño con una concreta familia adoptiva como una decisión que compete, en exclusiva, a las autoridades del Estado de origen. Es una disposición que reitera lo estipulado en el artículo 6 del protocolo peruano. Este precepto pudiera tener su justificación en el presupuesto, precisamente, de que es el Estado de origen el que, con la documentación aportada por el Estado de recepción —informes psicológicos, sociales, económicos, certificado de idoneidad, etcétera - debe estudiar la empatía que puede haber entre uno de sus menores y los solicitantes de adopción en Bolivia. Hay un esfuerzo, un acuerdo en común, entre Estado de recepción y de origen, que no tiene por qué ser simultáneo y que culmina con una preasignación que deberá ser autorizada por el Estado de recepción, sin la intervención del Estado de origen, así como la aceptación por parte de los solicitantes propuestos. Digamos que es una interpretación amplia de lo estipulado en el artículo 17 c) del Convenio de La Haya de 1993, que no obstaculiza esa decisión conjunta en la atribución del menor.

Si interpretamos de esta manera, no habría, entonces, motivos para creer que esta práctica generalizada, como vemos en la mayor parte de los Estados de origen de los menores, pueda provocar distancias con respecto al contenido del Convenio de La Haya de 1993.

Por último, destacar que el acuerdo boliviano es el primero de estos acuerdos bilaterales en materia de adopción internacional firmados por España que aparece publicado en el Boletín Oficial del Estado, lo cual es denotativo de un ánimo de formalidad y publicidad, atendiendo, sobre todo, a una voluntad de darle carácter de verdadero acuerdo o tratado sujeto de derecho internacional ${ }^{98}$ de acuerdo al artículo 39.2 del Convenio de La Haya de 1993;99 encubierto en esa voluntad que encierra los acuerdos administrativos. ${ }^{100}$

97 Calvo Caravaca, A. L., "Globalización y adopción...", cit., nota 28, p. 36.

98 González Beilfuss, C., "La aplicación en España...", cit., nota 24, p. 39.

99 Aún siendo un acuerdo anterior a la ratificación del Convenio de La Haya de 1993.

100 Remitimos a los comentarios expuestos en: 3. Apuntes sobre la naturaleza jurídica de los acuerdos bilaterales. 
No olvidemos tampoco que el acuerdo boliviano de 2001 es el tercero implementado entre España y Bolivia con una clara pretensión de revisión constante y actualización de la materia.

F. Filipinas. Protocolo sobre adopción internacional entre el Reino de España y la República de Filipinas, hecho en Manila, el 12 de noviembre de 2002, Boletín Oficial del Estado núm. 21, de 24 de enero de 2003, con entrada en vigor, Boletín Oficial del Estado núm. 265, de 5 de noviembre de 2003

En 2001, los datos proporcionados por el Ministerio de Trabajo y Asuntos Sociales reflejan que con respecto a Filipinas no se realizó ninguna adopción en España. Téngase en cuenta que este país contempla, según su normatividad, cuatrocientas colocaciones anuales a través de su autoridad central, la Junta de Adopción Internacional (Inter-Country Adoption Board, ICAB). Con estos datos se refleja la necesidad de instaurar acuerdos como el presente para darle cobertura a la adopción internacional entre España y Filipinas.

Filipinas es uno de los países con mayor tradición y una práctica muy consolidada en el ámbito de la adopción internacional101 $\mathrm{y}$, además, con respecto a España, y con el hecho de suscribir un protocolo de estas características, motiva el hecho de una afinidad cultural que proviene desde los tiempos en los que era colonia española.

El protocolo se encuentra dividido en cuatro títulos, quince artículos $\mathrm{y}$ tres apéndices.

El protocolo suscrito entre España y Filipinas en su "Preámbulo" establece, en primer lugar, quienes son las partes que suscriben dicho protocolo, para posteriormente asumir una serie de compromisos a través de principios generales en materia de adopción internacional.

Así, las partes manifiestan su voluntad de asumir los principios establecidos a nivel internacional, de nuevo a través de la Convención de Naciones Unidas sobre los Derechos del Niño de 1989 en el que se concibe la adopción internacional, por medio del principio de subsidiariedad, como medio de protección a la infancia reconociendo el derecho del niño a permanecer, prioritariamente, en su familia de origen o al menos a ser adoptado en su lugar de origen, y de no ser así, se reconoce que la 
adopción internacional puede presentar la ventaja de dar una familia permanente a un niño que no puede encontrarla en su Estado de origen, siempre respetando su identidad étnico-cultural.

Se enuncia, asimismo, la firma y ratificación de los dos Estados parte, al Convenio de La Haya de 1993 y que por ello se da: ${ }^{102}$

a) Por una parte, la condición expresada en el artículo 39.2 del mismo, en el cual el protocolo o acuerdo debe ser posterior a la entrada en vigor del Convenio de La Haya entre España y Filipinas, revistiendo, en principio, la naturaleza jurídica de acuerdo bilateral especial con un objetivo específico de favorecer la aplicación del mismo en las relaciones recíprocas, en el que no vemos, no obstante, a tenor del mismo artículo 39.2, la obligación de los Estados que concluyan estos acuerdos de transmitir una copia de los mismos al depositario de la Convención de La Haya de 1993.

b) Por otra parte, y en conexión con lo anterior, un compromiso en cumplir con las exigencias internacionales que van en torno al interés superior del niño, como principio toral, sustentado en la premisa de que el menor crezca en un medio familiar estable. La familia se configura como el instrumento social idóneo para la formación y el desarrollo personal del menor, en la medida en que no sólo es un medio de transmisión de valores y de pautas de conducta, sino que constituye el núcleo humano en el que el menor puede cubrir más ampliamente sus necesidades afectivas. ${ }^{103}$

Asimismo, el niño al que se refiere la adopción internacional deberá gozar de los derechos, salvaguardas y condiciones equivalentes a las que ya existan en el caso de la adopción nacional con el compromiso, de ambas partes, de ofrecer las máximas garantías recíprocas para la adopción de niños en el otro país.

Con respecto a las autoridades centrales de cada país, se expresa que éstas son las encargadas de la colocación de un menor, reforzándose en

102 España ratifica el Convenio de La Haya de 1993, el 1o. de noviembre de 1995, y Filipinas lo hace el 1o. de noviembre de 1996.

103 No obstante, también la familia se erige en ocasiones como elemento perturbador en el desarrollo del menor, generando actuaciones que menoscaban y lesionan los derechos de éste. De ahí que la sociedad no pueda permanecer impasible ante este tipo de situaciones, instando la puesta en práctica de los mecanismos necesarios para velar por los derechos del niño. Véase Preámbulo, Andalucía. Decreto 282/2002 de 12 de noviembre de Acogimiento Familiar y Adopción, Boletín Oficial de la Junta de Andalucía, núm. 135, de 19 de noviembre de 2002. Corrección de errores Boletín Oficial de la Junta de Andalucía, núm. 137, de 23 de noviembre de 2002. 
el Protocolo de Filipinas el mayor involucramiento de las autoridades del Estado de recepción a la hora de la colocación del menor, artículo 17 c) Convenio de La Haya de 1993, que lo habitualmente acostumbrado.

De igual manera, se pone énfasis en el carácter no lucrativo de estas adopciones, en las que no se deberá generar ningún beneficio indebido a favor de las personas que participen en el procedimiento.

El título I, referido al "Ámbito de aplicación”, está compuesto por dos artículos en los que se puede visualizar, perfectamente, que el artículo 1o. se refiere al ámbito de aplicación material y el artículo 2 , inciso a, se refiere al ámbito de aplicación territorial.

Con respecto al ámbito material reitera los fines primordiales instaurados, a su vez, en el Preámbulo del Convenio de La Haya de 1993 que rige, básicamente, a la comunidad internacional en materia de protección de menores, nos referimos al:

a) Sistema de cooperación entre las partes que garantice la plena eliminación y prevención de la sustracción, la venta y el tráfico ilegal de niños.

b) Reconocimiento de las adopciones plenas realizadas en el marco de dicho protocolo y de conformidad con las legislaciones de ambos países.

En cuanto al ámbito territorial, se expresa las condiciones necesarias para concebirse una adopción internacional, es decir, la necesidad de que el menor y los solicitantes tengan residencia en países distintos, de acuerdo a lo formulado en el artículo 2, párrafo primero, del Convenio de La Haya de 1993, así enuncia el protocolo, en su artículo 2, inciso a, "será aplicable en el caso de la adopción plena de un niño que tenga su residencia habitual en España o en Filipinas por personas habitualmente residentes en el otro país". Esto no da una idea del carácter bifronte, en el sentido de que tanto se puede ser país emisor de menores como receptor de los mismos. ${ }^{104}$

El artículo 2, inciso b, no marca ninguna pauta con respecto al mencionado ámbito territorial, y sin embargo, define qué se debe entender

104 La profesora González Beilfuss opina, en contra, que "Aunque el convenio (de La Haya de 1993) no impida que un Estado pertenezca simultáneamente a ambas categorías, la vigencia del principio de subsidiariedad que establece que hay que dar preferencia a la colocación del niño en una familia de su Estado de residencia habitual... dificulta que, salvo que concurran circunstancias excepcionales, un mismo Estado presente ese carácter bifronte", González Beilfuss, C., "La aplicación en España del Convenio de La Haya...", cit., nota 24, p. 315. 
por "niño". Entendemos que este tipo de apreciación se hubiera ubicado mejor en el preámbulo, lugar donde se especificaron principios y pautas que marcan dicho protocolo, como bien pudiera ser, precisamente, la conceptuación de niño o menor.

El título II, “Autoridades Centrales y organismos oficialmente autorizados" (artículos 3-8), trata de protocolizar todo lo referente a las autoridades centrales pero en ocasiones omite cuestiones de cierta relevancia, en otras reitera e incluso se extralimitan en cuestiones que deben expresarse, de preferencia, en un apéndice del mismo protocolo.

El artículo 3 comienza, en el inciso a, de manera acertada, por expresar quiénes son las autoridades centrales designadas por ambas partes:

Por el Reino de España: Cada una de las instituciones españolas, con respecto a las personas residentes en sus territorios respectivos, que haya cumplido el requisito previsto en el artículo 6.2.b (sic 6.2) del Convenio relativo a la Protección del Niño y a la Cooperación en Materia de Adopción Internacional, hecho en La Haya el 29 de mayo de 1993. Dichas instituciones se enumeran en el Apéndice A.

Para luego en el inciso b, aclarar que "la Dirección General de Acción Social del Menor y de la Familia, dependiente del Ministerio de Trabajo y Asuntos Sociales, será la autoridad central para la transmisión de informes y para la comunicación con ICAB (autoridad central Filipina)..."; quizás por cuestiones de orden, hubiera sido preferente establecer que de acuerdo a lo previsto en el artículo 6.2 del Convenio de La Haya de 1993, y de acuerdo, asimismo, a las declaraciones efectuadas por España al depositar el documento de ratificación del Convenio de La Haya de 1993, se designó al Ministerio de Trabajo y Asuntos Sociales. Dirección General de Acción Social del Menor y la Familia, como autoridad central de comunicación y una autoridad central por cada una de las Comunidades Autónomas para su territorio y sus residentes (enumeradas en el Apéndice A y que son un total de 23).

Este podría ser el principio general y posteriormente, en el inciso b, expresar que en el caso de que:

Cualquiera de las Autoridades Centrales españolas designadas que figuran en el Apéndice A tramite las solicitudes directamente con ICAB, el Ministerio de Trabajo y Asuntos Sociales de España lo comunicará previamente a ICAB y dicho acuerdo surtirá efectos después de la 
recepción por la autoridad central de que se trate de una carta de ICAB acusando recibo a dicha comunicación.

En el artículo 3, inciso b, en opinión de la profesora González Beilfuss, al leerlo con detenimiento observamos que hasta cierto punto corrige la declaración efectuada por España, al ratificar el Convenio de La Haya de 1993, en relación al artículo 6.2 del convenio. El convenio prevé que los Estados que designen más de una autoridad central habrán de designar a una autoridad central a la que podrá dirigirse toda comunicación para su transmisión a la autoridad central competente dentro de ese Estado. ${ }^{105}$ El texto del convenio no impide, por tanto, la comunicación directa sin la intermediación de dicha autoridad central, de ahí que sea totalmente factible e incluso más conveniente, con un espíritu de confianza mutua y cooperación efectiva, además de una economía procesal. Dado el papel activo del procedimiento de adopción internacional filipino, es indispensable, además, esa comunicación directa entre la autoridad central filipina y la autoridad central correspondiente al territorio español en el que tiene establecida su residencia los solicitantes, independientemente de la comunicación que proceda hacerse al Ministerio de Trabajo y Asuntos Sociales, a su Dirección General de Acción Social del Menor y de la Familia; pero lo que no puede realizar el ministerio es impedir que las autoridades centrales de las Comunidades Autónomas, que así lo deseen, puedan colaborar con la autoridad central filipina sin su intermediación. ${ }^{106}$

La cuestión en sí es que por cuestiones, simplemente, de dar transparencia a la adopción tramitaba entre ambos Estados parte, la autoridad central del Estado de recepción; en este caso, debería ser la primera en saber este contacto directo del que habla entre autoridades centrales; ya no hablamos de que el artículo 6.2 del Convenio de La Haya estipula que habrán de designar a una autoridad central a la que podrá dirigirse toda comunicación para su transmisión a la autoridad central competente dentro de ese Estado, sino que por dar seguridad jurídica o transparencia, como decimos, se notifique esa tramitación.

El artículo 3, inciso c, contempla dos supuestos:

105 González Beilfuss, C., "La aplicación en España...", cit., nota 24, pp. 9-41; id., "El protocolo de adopción...", cit., nota 34 .

106 Idem. 
1. La posibilidad de que las autoridades centrales puedan delegar "todas o parte de sus obligaciones" en organismos públicos o privados, ${ }^{107}$ se refieren a las Entidades Colaboradoras de Adopción Internacional, ECAI, debidamente autorizados por la parte proponente, entendemos que por el Estado de recepción, y aprobados por la otra parte, entendemos que Estado de origen. Subrayar que no se pueden delegar "todas" sus obligaciones, que hay una serie de funciones indelegables que deben llevar a cabo las respectivas entidades públicas. ${ }^{108}$

2. Por otra parte, se manifiesta clara y directamente la necesidad de una doble acreditación por parte de aquellas ECAI que pretendan mediar; primero deben estar autorizadas o acreditadas por el país de residencia de los solicitantes, Estado de recepción, y posteriormente, aprobados o ratificados por el Estado de origen de los menores.

El último inciso del artículo 3, inciso d, no deja suelta una cuestión de máximo interés como es establecer a quien corresponde actuar como supervisores de los organismos autorizados por ellos, las ECAI, invocando las reglas establecidas en el mismo protocolo, en los convenios internacionales y en las leyes de protección al menor, aquí añadiríamos la coletilla de "estatales y autonómicas, en su caso". ${ }^{109}$ En España, las

107 La delegación de facultades en organismos debidamente acreditados se presenta sólo para los Estados parte como una facultad convencional, y nunca como una obligación. En este sentido, cada uno de ellos puede optar entre los modelos que acoge la norma: 1. Sistema de autoridades participativo en el que los organismos acreditados intervienen imperativamente (por ejemplo, Rumania); 2. Sistema articulado exclusivamente a través de autoridades públicas (por ejemplo, Panamá, casos sui generis, como Filipinas o Costa Rica), 3. Sistema dualista que permite las dos opciones anteriores (por ejemplo, España). García Cano, Sandra, Protección del menor..., cit., nota 87, pp. 143 y 145.

108 Hay una serie de funciones indelegables que deben llevar a cabo las respectivas entidades públicas, tales como: expedición del certificado de idoneidad, informe de adoptabilidad y, cuando lo exija el país de origen del menor, expedición del compromiso de seguimiento. Ibidem, p. 148. Asimismo, véase Carrillo Carrillo, B. L., Adopción internacional..., cit., nota 28, pp. 87-91.

109 Todas las Comunidades Autónomas han legislado sobre la materia de protección de menores: Así Andalucía, Ley 1/1998, de 20 de abril, de regulación de los Derechos y la Atención al Menor (BOE, núm. 150, de 24 de junio de 1998); Aragón, Ley 10/1989, de 14 de diciembre, de Protección de Menores (BOE, núm. 5, de 5 de enero de 1990); Asturias, Ley 1/1995, de 27 de enero, sobre Protección de Menores (BOE, núm. 94, de 20 de abril de 1995); Canarias, Ley 1/1997, de 7 de febrero, de Atención Integral a los menores (BOE, núm. 63, 14 de marzo de 1997); Cantabria, Ley 7/1999, de 28 de abril, de Protección de Infancia y Adolescencia, (BOE, núm. 127, de 28 de mayo de 1999); Castilla-La Mancha, Ley 3/1999, de 31 de marzo, de Menores, (BOE núm. 124, de 25 de mayo de 1999); Castilla León; Cataluña, Ley 8/1995, de 27 de julio de 1995, de Atención y Protección de los Niños y los Adolescentes (BOE, núm. 207, de 30 de agosto de 1995); Extremadura, Ley 4/1994, de 10 de noviembre, de Protección y Atención a Menores (BOE, núm. 309, de 27 de diciembre de 1994); Galicia, Ley 3/1997, de 9 de junio, de Familia, Infancia y 


\section{Comunidades Autónomas a través de sus diferentes decretos de habilita- ción o acreditación de ECAI, regula con eficacia sorprendente, tanto el control e inspección de las mismas como el procedimiento de reclama- ciones y quejas, inspección y régimen sancionador. ${ }^{110}$}

Adolescencia: Protección Jurídica, Económica y Social, (BOE, núm. 165, de 11 de julio de 1997); Islas Baleares, Ley 7/1995, de 21 de marzo, de Guarda y Protección de los Menores Desamparados (BOE, núm. 119, de 19 de mayo de 1995); La Rioja, Ley 4/1998, de 18 de marzo, del Menor (BOE, núm. 79, de 2 de abril de 1998); Madrid, Ley 6/1995, de 28 de marzo, de Garantías de los Derechos de la Infancia y la Adolescencia (BOE, núm. 183, de 2 de agosto de 1995); Comunidad Valenciana, Ley 7/1994, de 5 de diciembre, de la Infancia (BOE, núm. 21, de 25 de enero de 1995); Murcia, Ley 3/1995, de 21 de marzo, de la Infancia (BOE, núm. 86, de 12 de abril de 1995).

110 Dada la necesidad de perfeccionar la regulación legal de las entidades colaboradoras a las que las administraciones competentes acreditan para la delicada función de la mediación, se han producido diversas revisiones de las respectivas normativas autonómicas, siguiendo las orientaciones desarrolladas en el marco de la colaboración entre las Comunidades Autónomas. Así tenemos que, con fecha de julio de 2003, los decretos de habilitación son: Andalucía, Decreto 454/1996, de 1 de octubre, para la Habilitación de Instituciones Colaboradoras de Integración Familiar y Acreditación de Entidades Colaboradoras de Adopción Internacional (BOJA núm. 120, de 19 de octubre de 1996); Aragón, Decreto 16/1997, de 25 de febrero, que regula la Habilitación de Entidades Colaboradoras de Adopción Internacional (BOA, núm. 26, de 5 de marzo de 1997); Asturias, Decreto 5/1998, de 5 de febrero, Reglamento de Instituciones Colaboradoras de Integración Familiar y de Entidades Colaboradoras de Adopción Internacional (BOPA, núm. 41, de 19 de febrero de 1998); Canarias, Decreto 200/1997, de 7 de agosto, por el que se regula la Habilitación de Entidades Colaboradoras de Adopción Internacional (BOC, núm. 109, de 20 de agosto de 1997); Cantabria, Decreto 47/1998, de 15 de mayo, sobre Acreditación y Funcionamiento de las Entidades de mediación en Adopción Internacional (BOC, núm. 105, de 27 de mayo de 1998); Castilla-La Mancha, Decreto 35/1997, de 10 de marzo, de Acreditación de las Entidades Colaboradoras de Adopción Internacional (BOCM, núm. 11, 14 de marzo de 1997); Castilla y León, Decreto 207/1996, de 5 de septiembre, de Habilitación de Entidades Colaboradoras de Adopción Internacional (BOCyL, de 11 de septiembre de 1996); Cataluña, Decreto 97/2001, de 3 de abril, sobre la Acreditación y el Funcionamiento de las Entidades Colaboradoras de Adopción Internacional (BOGC, núm. 3369, de 17 de abril de 2001); Extremadura, Decreto 55/2002, de 30 de abril, que modifica el Decreto 142/1996 de 1o. de octubre (DOE, núm. 52, de 7 de mayo de 2002); Galicia, Decreto 42/2000, de 7 de enero de Asistencia Social que refunde la Normativa Vigente en Materia de Familia, Infancia y Adolescencia ( $D O G$, núm. 45 de 6 de marzo de 2000); Islas Baleares, Decreto 187/1996, de 11 de octubre, de Acreditación de Entidades Colaboradoras de Adopción Internacional (BOCAIB, de 14 de noviembre de 1996); Madrid, Decreto 262/2001 de 22 de noviembre, sobre la Acreditación y Funcionamiento de las Instituciones Colaboradoras de Adopción Internacional (BOCM, núm. 285, de 30 de noviembre de 2001); Murcia, Decreto 487/2002, de 1o. de febrero, que modifica los decretos 81/1994, de 4 de noviembre de Procedimiento de Formulación de Propuesta, y 66/1997 de 12 de septiembre sobre Acreditación y Actuación de las Instituciones Colaboradoras en la Adopción Internacional (BORM, núm. 41, de 18 de marzo de 2002); Navarra, Decreto Foral 168/2002 de 22 de julio, por el que se regula la Acreditación de las Entidades Colaboradoras en Materia de Adopción Internacional (BON, núm. 110, de 11 de septiembre de 2002); La Rioja, Decreto 29/1997, de 9 de mayo de 1997, que regula la Habilitación de Entidades Colaboradoras de Adopción Internacional (BOLR, núm. 58, de 15 de mayo de 1997); Comunidad Valenciana, Decreto 100/2002, de 4 de junio, por el que se regula la Acreditación, Funcionamiento y control de las Entidades de mediación de Adopción Internacional y el Registro de Reclamaciones formuladas contra las Entidades de Mediación acreditadas en la Comunidad Valenciana (DOGV, 
El artículo 4, inciso a, por un lado, pretende remarcar el principio de cooperación que debe proyectar siempre las autoridades centrales entre ellas, pero lo mezcla con la enunciación del procedimiento de cooperación. Quizás lo más acertado hubiera sido deslindar en este artículo un inciso a, que expresara los principios orientadores de la práctica mediadora, por delegación de las autoridades centrales, según se estipula en el artículo 9 del Convenio de La Haya de 1993, a saber:

1. Reunir, conservar e intercambiar información relativa a la situación del niño y de los futuros padres adoptivos.

2. Facilitar, seguir y activar el procedimiento de adopción.

3. Promover el desarrollo de servicios de asesoramiento en materia de adopción para el seguimiento de las adopciones.

4. Intercambiar informes generales de evaluación sobre las experiencias en materia de adopción internacional.

5. Responder a las solicitudes de información realizadas por otras autoridades centrales o autoridades públicas.

Añadir, además, una cuestión de máxima relevancia como es la siguiente: "Remitiendo informes de seguimiento, debidamente legalizados, por la representación diplomática y/o consular, cada seis meses, durante los dos primeros años siguientes a la adopción pronunciada judicialmente". Y posteriormente, un inciso $b$, que enunciara solo el procedimiento para a continuación, dedicarle un título completo, como es el título III "Requisitos y procedimientos".

Con este presupuesto, dejaríamos sin contenido el artículo 5 que expresa lo estipulado en el mencionado artículo 9 del Convenio de La Haya de 1993.

No obstante, hay que destacar, con respecto al mismo artículo 5 que el acuerdo expresa que las autoridades centrales se faciliten mutuamente elementos de evaluación con respecto de las adopciones realizadas al amparo del protocolo. ${ }^{111}$

núm. 4271, 14 de junio de 2002); País Vasco, Decreto 302/1996, de 24 de diciembre, por el que se regula la Habilitación de las Entidades Colaboradoras de Adopción Internacional ( $B O P V$, de 3 de enero de 1997).

111 Como dato de interés tenemos el caso de México, que a través del DIF-Nacional (autoridad central en materia de adopción internacional) se está realizando un Padrón de Niños vulnerables (softwares especializados) orientado a cada uno de los grupos que le corresponde atender al DIF (discapacitados, menores albergados, adopciones, etcétera). Con respecto al módulo titulado "Menores albergados", ya está instalado como proyecto piloto en el Estado de Baja California y contiene la información completa de todos aquellos niños albergados en cincuenta casas 
El artículo 6 expresa en esencia que "las adopciones contempladas en el presente protocolo se llevarán a cabo cuando" se cumplan ciertas condiciones y/o requisitos solicitados para la adopción internacional en cada uno de los Estado parte, fundamentalmente, en cuanto a los informes de adoptabilidad, en el Estado de origen, una vez descartada la adopción nacional, y en cuanto al certificado de idoneidad, en el Estado de recepción. Posteriormente, remite a un apéndice B para enumerar los requisitos y documentos complementarios exigidos por cada uno de los Estados parte.

El artículo 7, por su parte, se centra en el reconocimiento de la adopción plena y lo expresa de la siguiente manera: "La autoridad central del Estado de recepción garantizará, de acuerdo con su legislación, el cumplimiento de todos los requisitos necesarios para el reconocimiento de la plena adopción, e informará de ello a la autoridad central del Estado de origen, enviándole la documentación pertinente"; no olvidemos la garan-

públicas y privadas del mencionado Estado. La información disponible está contenida en un expediente electrónico individual, de cada niño, conformando una base de datos estatal con todos los datos de los menores a los que sólo tienen acceso las personas autorizadas del DIF. Como complemento de esta base de datos de niños albergados, hay un módulo de "adopciones" con la información tanto de los candidatos susceptibles de ser adoptados como de los solicitantes de adopción, nacional e internacional. La idea del DIF-Nacional es instalar, si los resultados son positivos, el Padrón en toda la República Mexicana, y así derivar los expedientes de adopción, nacional e internacional, a aquellos Estados donde realmente hay posibilidades de adoptar a un menor con las características que consta en la idoneidad de los solicitantes. Se piensa en el Padrón como una herramienta que facilite y agilice los procesos de adopción allí donde realmente hay niños susceptibles de darse en adopción, ubicando expedientes sólo donde hay posibilidades reales de adoptar y darle una familia a un niño que la necesita. El fin sería potenciar mecanismos eficaces que combatan situaciones que provocan la institucionalización de niños y, por ende, ubicar expedientes de adopción, sin demoras innecesarias, en aquellos Estados que lo soliciten. Un padrón que determina el origen del menor, sin que se preste a prácticas ilícitas, hasta la situación del menor en su país de destino. Mencionar, por otra parte, que hay instituciones dedicadas, desde hace años, a facilitar su experiencia, entre otras cuestiones, en la habilitación de este tipo de Padrón o base de datos; entre ellas destacamos Intercountry Adoption Congress (IAC). Véase su página http://www.iacongress.org. El IAC ha obtenido licencia para este sistema de información en el tema de adopciones. Es una organización cuya misión es la de ayudar a los gobiernos de los países interesados en mejorar sus sistemas de adopción, suministrando la tecnología necesaria - softwares especializados - que permiten el acceso a la información, al personal autorizado, y efectúa, una vez analizadas las características de niños y futuros padres, la propuesta más idónea, dando celeridad al proceso. Igualmente con una base de datos como la descrita se puede obtener un reporte que incluya los datos referentes a niños que ya han sido colocados, adoptados, en hogares, tanto en el territorio nacional como en el extranjero, y así darle el seguimiento durante el tiempo que corresponda; datos sobre las adopciones iniciadas, pendientes y/o finalizadas; comparar resultados logrados por los diferentes Estados del país u obtener información detallada de la situación en la que se encuentran, por ejemplo, los diferentes DIF. 
tía internacional del derecho del menor de gozar de los derechos y salvaguardas equivalentes de la adopción nacional, normalmente plena.

El artículo 8, en la misma línea y tratando, una vez más, de garantizar el goce de sus derechos, enuncia que si en el:

Curso del procedimiento de adopción, se compruebe la existencia de cualquier impedimento, como por ejemplo que, en consideración al interés superior del niño, no resulte apropiado reconocer la adopción, la autoridad central que aprecie dicho impedimento lo comunicará inmediatamente a la autoridad central del otro Estado con objeto de determinar de mutuo acuerdo las medidas más adecuadas para salvaguardar los derechos del niño, en estrecha coordinación con la autoridad central del otro Estado, hasta que se acuerden las medidas de protección definitivas.

Mantenemos nuestras reticencias ante la necesidad de este tipo de supuestos tal y como venimos reiterando en las páginas anteriores.

Como ya mencionamos, el título III "Requisitos y procedimiento" (artículos 9-12) enlaza y coordina lo expuesto y así manifiesta en su artículo 9 que "en la tramitación de los expedientes de adopción entre las autoridades centrales de ambos países se aplicarán los requisitos y se exigirá la documentación complementaria previstos en el Apéndice B, que forma parte integrante del presente protocolo. El Apéndice C contiene los procedimientos para la tramitación de las solicitudes".

Para actualizar tanto los requisitos como la documentación exigida, Apéndice B, el artículo 10 prevé la posibilidad de adaptar:

En cada momento a la legislación y/o a los criterios sobre procedimiento aplicables en ambos países, y podrán modificarse posteriormente mediante el simple canje de notificaciones entre el Ministerio de Trabajo y Asuntos Sociales y el Departamento de Bienestar Social y Desarrollo, previa aprobación por escrito por las Autoridades Centrales de las dos partes.

Por lo tanto, el Apéndice B cumple con una misión que es facilitar información, desde el protocolo, acerca de los requisitos y documentos complementarios exigidos. Dichos requisitos y documentos pueden variar acomodándose a las necesidades explícitas por el transcurso del tiempo, nos referimos a la necesidad de actualizar, cuestión que el mismo artículo 10 lo solventa cuando expresa que el Apéndice B puede modificarse mediante un simple canje de notas. Por otro lado, y con respecto al 
mismo Apéndice B, sorprende que se detallen tanto los requisitos de adoptabilidad como de la capacidad para adoptar tanto en la legislación filipina como en la española, justificado, quizás, por el papel preponderante que se le otorga al Estado de recepción en la fase de colocación del menor dado que la constitución de la adopción, según la legislación filipina, ha de tener lugar en el Estado de recepción, cuestión que comentaremos al analizar el contenido del Apéndice C. ${ }^{112}$

Con respecto al Apéndice $\mathrm{C}$ relativo al "Procedimiento relativo a la adopción de un niño filipino" destaca, en primer lugar, que dentro del procedimiento de adopción filipino, el traslado del niño al Estado de recepción es anterior a la constitución de la adopción e incluso se expresa que toda la fase preadoptiva se desarrollará en España bajo la supervisión de las autoridades españolas. ${ }^{113}$ El Apéndice C en su punto 9 lo expresa de la siguiente manera: "la autoridad central española supervisará la colocación del niño bajo la custodia de los posibles padres adoptivos y se encargará de que se envíen informes a la autoridad central filipina cada dos meses durante un periodo de seis meses, a partir de la fecha de llegada del niño a España". Dicho acuerdo discrepa del resto de los firmados por España en que no se exige que la adopción se constituya en el Estado de recepción por las autoridades competentes, ${ }^{114}$ lo cual no constituye, en absoluto, una referencia negativa.

Siempre hablamos del principio toral del interés superior del menor que consiste, entre otras cuestiones, en aceptar la adopción internacional cuando realmente no tenga opciones en su familia biológica o tampoco

112 Aunque no descartamos tampoco una intención de canalizar los requisitos exigidos por ambos Estados parte y así lograr un sistema distributivo y no acumulativo. Véase este aspecto, en general, en Álvarez González, S., op. cit., nota 24, pp. 194 y 195.

113 González Beilfuss, C., "El protocolo de adopción...", cit., nota 34, manifiesta en su artículo una postura a favor de este procedimiento protocolizado con Filipinas, y expresa que el traslado del menor al Estado de recepción con anterioridad a la constitución de la adopción, o incluso el hecho de que se desarrolle la fase preadoptiva en España bajo la supervisión de las autoridades españolas, propiciará "mejores condiciones para tutelar y asesorar a los solicitantes de adopción internacional en el que será el medio natural del niño". Nosotros discrepamos de esta opinión, tal y como vamos a reflejar en las páginas siguientes.

114 Para determinar la aplicación del Convenio de La Haya de 1993, "es indiferente que la adopción se formalice en el Estado de origen o en el Estado de recepción, lo relevante es que la adopción comporte un traslado internacional del menor de un país a otro, bien antes de la adopción o como consecuencia de ella. El Convenio de La Haya de 1993 se aplica, incluso, cuando el menor va a ser adoptado y se traslada a dicho menor a otro país, pero finalmente, la adopción no se constituye". Calvo Caravaca, A. L., "Globalización y adopción...", cit., nota 28, p. 49; Carrillo Carrillo, B. L., Adopción internacional..., cit., nota 28. 
con una familia de su país de origen, cuestiones fundadas, básicamente, en no desarraigar al menor de su cultura, de sus raíces y así evitar un posible "trauma" de estos menores que repentinamente cruzan fronteras y forman parte de una nueva familia. ${ }^{115}$ Pensamos que el proceso debe llevar su tiempo y es importante que el menor conozca en su entorno, no en el entorno de sus posibles padres adoptivos, a su familia futura.

El menor, independientemente de la edad que tenga, necesita ir asimilando todo el cambio de una manera paulatina y si esta asimilación se pudiera dar dentro de su "territorio" ello, quizás, beneficie la adaptación. Cambios demasiados bruscos y seguidos puede provocar, precisamente, el efecto contrario pretendido en el procedimiento de adopción internacional filipino, que es el fracaso en el proceso ya no sólo postadoptivo sino preadoptivo y no se culmine, en definitiva, la colocación del menor a través de la adopción internacional. El mismo Apéndice C, en su apartado 11, confiere a las autoridades centrales españolas una amplia discrecionalidad incluso para decidir informar negativamente respecto a la constitución de la adopción. Si la colocación sufriera algún contratiempo, la autoridad central española, tras informar a la autoridad central filipina en un plazo máximo de 72 horas, debe hacer todo lo posible para prestar asistencia a la familia y al niño (diríamos mejor al niño y a la familia) e incluso puede decidir buscar otra familia adoptante (y dudamos si la empatía con el menor y otra familia pudiera darse "sobre la marcha") ${ }^{116} \mathrm{o}$, en última instancia, ordenar la repatriación del niño. El daño

115 Comentar, en este momento, lo loable de esta acción, es decir el desarrollo de la fase preadoptiva y la constitución de la adopción en España, en cuanto a la "facilidad" que supone para los padres futuros constituir una adopción internacional desde sus hogares, sin tener que ausentarse de sus labores; pero insistimos en la idea que estamos planteando que parte, sin lugar a dudas, del principio del interés superior del menor.

116 De nuevo, aunque con las dudas expuestas, el artículo 17.c del Convenio de La Haya de 1993 prevé que la decisión relativa a la colocación ha de ser una decisión conjunta de las autoridades centrales del Estado de origen y del Estado de recepción, el denominado matching. En efecto, el matching parte de que la decisión relativa a la colocación, al ser una decisión conjunta, sólo se producirá respecto a aquellas situaciones en las que se produzca una convergencia de opiniones entre las autoridades centrales de los dos Estados implicados. Meyer Fabre, N., "La Convention de La Haye...", cit., nota 24, pp. 282 y 283, citada por González Beilfuss, C., "El Protocolo de adopción internacional...", cit., nota 34. Buscar una alternativa para un menor que en la fase preadoptiva sufrió un fracaso y no siguió el procedimiento su ruta, lleva todo un proceso, basado normalmente en una lista, en un orden de llegada, de solicitantes en espera para adoptar en Filipinas, que se dificulta por la premura que se presenta en este proceso concreto; esto sin descartar que una vez encontrada la posible familia para el menor, éste tenga que ser trasladado de la Comunidad Autónoma, dependiendo del lugar de residencia de su nueva opción familiar; ésta peregrinación tampoco la 
que puede sufrir un menor al sentirse rechazado, sin tener a su alcance el personal que realmente lo conoce, nos referimos al equipo multidisciplinar que normalmente se encuentran en las casas-cuna o casas-hogares de donde proceden estos menores, en un país que no es el suyo y encontrarse de nuevo en el punto de partida sin una opción familiar, debe valorarse antes de iniciar un proceso preadoptivo en el Estado de recepción de los menores. ${ }^{117}$

Dentro del procedimiento establecido en el protocolo, hay una cuestión que no queda muy clara y es la necesidad de realizar informes de seguimientos del menor durante una temporalidad. Es cierto que el Apéndice $\mathrm{C}$ expresa con respecto a la "Fase posterior a la adopción: La autoridad central española e ICAB implantarán y coordinarán un programa postadopción", pero no sabemos si se refiere a un programa de asistencia postadoptiva previendo o apoyando ya a aquellas familias que pudieran tener problemas derivados de la adopción, porque si se trata de este programa es importante obtener este tipo de asistencia, pero ello es independiente de un compromiso que va a más allá de un servicio postadoptivo, sino la necesidad de un seguimiento del menor para constatar que se cumplieron con las premisas de que dicha adopción internacional se realizó buscando el bienestar del niño y que ello se cumple. Como ejemplo concreto con respecto a los diferentes protocolos que estamos comentando, el artículo 5 del protocolo peruano hace mención expresa a la necesidad de emitir un reporte semestral por un periodo de cuatro años, sin embargo no se establece esta medida de tanta relevancia, en el protocolo filipino. ${ }^{118}$

El artículo 11, en cuanto a la conservación y confidencialidad de la información relativa a los orígenes del niño y su familia, en caso de conocerse, se estima que será posible acceder a la misma, con las debidas

encontramos de lo más idónea para un menor que constantemente sigue viendo a personas que no identifica, que no conoce, y que ni tan siquiera entiende por cuestiones de idioma.

117 Todo esto sin mencionar otras cuestiones marginales como a quién le corresponde pagar los gastos derivados de un fracaso preadoptivo, como el billete de avión de regreso a su país de origen, su manutención durante la espera, etcétera. El Apéndice C que corresponde al "Procedimiento relativo a la adopción de un niño filipino" que estamos comentando, en su apartado 7 expresa que "correrán por cuenta de los posibles padres adoptivos los costes, tasas, cargas y exacciones derivados de la colocación en fase de preadopción, según se establece en la legislación filipina", pero no habla, en caso de un presunto fracaso, sobre quien "cargará" con los gastos; quizás la administración pública española.

118 Nosotros hemos propuesto, en este trabajo, su inclusión dentro del artículo 4, inciso a). 
autorizaciones, dentro de los límites establecidos por las legislaciones de ambos Estados.

El artículo 12 se refiere, en su inciso a), a la denuncia cuando "no se ha respetado o que existe un riesgo manifiesto de que no se respete cualquiera de las fases del procedimiento de adopción internacional previstas en el presente protocolo, lo comunicará inmediatamente a su autoridad central, la cual, a su vez, cooperará con la otra autoridad central para adoptar las medidas que se estimen necesarias".

De la simple lectura del siguiente inciso b, no queda claro que el protocolo que se comenta esté encuadrado dentro de un convenio o tratado internacional, ya que la solución de controversias entre autoridades centrales "relativa a la interpretación o aplicación del presente protocolo se resolverá mediante consulta o negociación"; no obstante, el título IV "Cláusulas finales" (artículos 13-14), presenta varios de los caracteres que definen a un convenio internacional. Así el artículo 13, por una parte, establece el proceso de modificación o revisión del texto, "se hará de mutuo acuerdo entre ambas partes. Dicha modificación o revisión entrará en vigor de conformidad con la disposición relativa a la materia"; por otra parte, establece el mecanismo de modificación de sus preceptos "Las Autoridades Centrales, de mutuo acuerdo y mediante el canje de cartas, podrán modificar los puntos contenidos en el Apéndice B, siempre que dichos cambios no modifiquen de forma sustancial las disposiciones del presente protocolo. No obstante, la modificación del protocolo o del Apéndice B no afectará a la tramitación del procedimiento de solicitud".

El artículo 14 establece la aplicación provisional "pasados treinta días después de su firma y entrará en vigor en la fecha de la última notificación escrita de las partes, por conducto diplomático, indicando que se han cumplido los requisitos internos para su entrada en vigor".

Al igual que el acuerdo boliviano, este acuerdo también se publicó en el Boletín Oficial del Estado corroborando ese ánimo o voluntad de constituirlo como acuerdo sujeto de derecho internacional.

\section{A MODO DE CONCLUSIÓN}

El Convenio de La Haya de 1993 establece una jerarquía de los principios del bienestar del niño, y atiende, a su vez, a los principios estipulados en el Convenio sobre los Derechos del Niño de 1989 que sirven de base para su marco de cooperación: 
a) Mantener al niño en el seno de la familia de origen (Preámbulo, párrafo 2 del Convenio de La Haya de 1993).

b) Encontrar una familia adecuada en el Estado de origen (Preámbulo, párrafo 3 del Convenio de La Haya de 1993).

c) Adopción entre países de conformidad al Convenio de La Haya de 1993.

d) Alternativas no familiares dentro y fuera del país de origen.

El marco de cooperación establecido por el Convenio de La Haya de 1993, al decir de Hans van Loon, tiene una finalidad primordial que consiste en asegurar que se respete dicha jerarquía y que las medidas de protección, los procedimientos y las instituciones contempladas en el Convenio de La Haya de 1993 sean congruentes con dicho orden jerárquico que tiene una única pretensión que es salvaguardar la identidad originaria y la dignidad personal del menor. Así el convenio de 1993 refuerza, en primer lugar, la necesidad, en interés superior del niño, de mantener sus lazos familiares y su identidad cultural y nacional y, en segundo lugar, también en interés del menor, aborda el cambio de identidad cuando se produce el traslado de un niño de un entorno familiar, cultural y nacional a otro.

Es un convenio con evidentes lagunas, pero también perfectible sin lugar a dudas, que no se aplica a aquellas "adopciones" o instituciones jurídicas que no hacen surgir un vínculo de filiación entre adoptando y adoptantes, como es el caso, por ejemplo de la kafala musulmana, para quedar, por lo tanto, fuera del ámbito material del Convenio de La Haya de 1993, y de ahí que haya sido calificado, como expone Calvo Caravaca, de convenio escasamente multicultural.

Es un convenio con las mejores intenciones teóricas pendientes de la práctica diaria y de su adecuación por los Estados parte que intervengan en un determinado proceso de adopción. Un convenio que trata de establecer un equilibrio entre su regulación y el respeto de la autonomía tanto a nivel de la responsabilidad del Estado como a nivel de las personas individuales implicadas en la adopción, y un convenio en el que a través de los protocolos o acuerdos bilaterales contemplados en su artículo 39.2, tiene una incidencia directa en la práctica de las adopciones internacionales constituidas por españoles, en este caso, al vincular a los más relevantes países "exportadores" de menores a España.

Desde un punto de vista técnico, los acuerdos bilaterales expuestos parecen un instrumento muy adecuado para que las adopciones que se 
constituyan a su amparo se realicen con todas las garantías y en interés superior del menor. Quizás con algunos protocolos o acuerdos bilaterales no logremos, cuantitativamente hablando, cifras importantes de adopciones internacionales entre ambos países, pero lo que sí se propicia son garantías, cualitativamente hablando, en la constitución de dichas adopciones.

Por último, con respecto a la calificación y naturaleza jurídica del acuerdo en sí, concluimos que frente a la diversidad de alternativas planteadas, sin duda la solución técnicamente más satisfactoria impone el abandonar los prejuicios nominalistas y formalistas para situarse frente a la sustancia de las actividades implicadas; es decir, sería el contenido de los acuerdos el que permitiría desvelar la naturaleza convencional o meramente declarativa, promocional, o sea, "no normativa" de los actos en cuestión, y ello con independencia de su conclusión por órganos diplomáticos o administrativos strictu sensu, o bien acuerdos administrativos que entrañan la asunción de obligaciones para los órganos contratantes en cuyo caso constituyen verdaderos tratados internacionales o contratos entre administraciones sometidos al derecho de una de las partes contratantes.

De lo que no podemos dudar es que el Convenio de La Haya de 1993 ha tenido una gran influencia en el ámbito internacional porque ha creado una política de cooperación, en materia de adopción internacional, no sólo entre los Estados partes del convenio sino entre Estados que aún no han firmado o ratificado el mismo, influyendo en la introducción de la figura de autoridades centrales e incluso reestructurando la organización y funcionamiento de sus agencias de adopción con base en el modelo del Convenio de La Haya de 1993; además de propiciar la firma de acuerdos bilaterales en materia de adopción internacional, basados, asimismo, en el modelo del Convenio de La Haya de 1993.

Si queremos tener algún dato más que indique la aceptación del Convenio de La Haya de 1993, nada más tenemos que añadir que el Comité de las Naciones Unidas sobre los Derechos del Niño ha aprobado el Convenio de La Haya de 1993, y recomienda su ratificación a los Estados. 